\title{
Chemical kinetic insights into the ignition dynamics of n-hexane
}

\author{
Efstathios-Al. Tingas ${ }^{\mathrm{a}, *}$, Zhandong Wang ${ }^{\mathrm{a}}$, S. Mani Sarathy ${ }^{\mathrm{a}}$, Hong G. Im ${ }^{\mathrm{a}}$, Dimitris \\ A. Goussis ${ }^{b, c}$ \\ ${ }^{a}$ King Abdullah University of Science and Technology (KAUST), Clean Combustion Research Center \\ (CCRC), Thuwal, Jeddah 23955-6900, Kingdom of Saudi Arabia \\ ${ }^{b}$ Department of Mechanics, School of Applied Mathematical and Physical Sciences, National Technical \\ University of Athens (NTUA), 15780 Athens, Greece \\ ${ }^{c}$ Department of Mechanical Engineering, Khalifa University of Science, Technology and Research \\ (KUSTAR), Abu Dhabi, United Arab Emirates 127788
}

\begin{abstract}
Normal alkanes constitute a significant fraction of transportation fuels, and are the primary drivers of ignition processes in gasoline and diesel fuels. Low temperature ignition of n-alkanes is driven by a complex sequence of oxidation reactions, for which detailed mechanisms are still being developed. The current study explores the dynamics of low-temperature ignition of n-hexane/air mixtures, and identifies chemical pathways that characterize the combustion process. Two chemical kinetic mechanisms were selected as a comparative study in order to better understand the role of specific reaction sequences in ignition dynamics: one mechanism including a new third sequential $\mathrm{O}_{2}$ addition reaction pathways (recently proposed by Wang et al. [1]), while the other without (Zhang et al. [2]). The analysis is conducted by applying tools generated from the computational singular perturbation (CSP) approach to two distinct ignition phenomena: constant volume and compression ignition. In both cases, the role of the third sequential $\mathrm{O}_{2}$ addition reactions proves to be significant, although it is found to be much more pronounced in the constant volume cases compared to the HCCI. In particular, in the constant volume ignition case, reactions present in the third sequential $\mathrm{O}_{2}$ addition reaction pathways (e.g., $\mathrm{KDHP} \rightarrow$ products $+\mathrm{OH}$ ) contribute significantly to the explosivity of the mixture; when accounted for along with reactions $\mathrm{P}(\mathrm{OOH})_{2}+\mathrm{O}_{2} \rightarrow \mathrm{OOP}(\mathrm{OOH})_{2}$ and $\mathrm{OOP}(\mathrm{OOH})_{2} \rightarrow \mathrm{KDHP}+\mathrm{OH}$, they decrease ignition delay time of the mixture by up to $40 \%$. Under HCCI conditions, in the first-stage ignition, the third- $\mathrm{O}_{2}$ addition reactions contribute to the process, although their role decays with time and becomes negligible at the end of the first stage. The second ignition stage is dominated almost exclusively by hydrogen-related chemistry.
\end{abstract}

Keywords: CSP, explosive dynamics, n-hexane, third sequential $\mathrm{O}_{2}$ addition reactions, autoignition, HCCI, low-temperature oxidation

\footnotetext{
*Corresponding author.

Email address: stathis.tingas@kaust.edu.sa (Efstathios-Al. Tingas)
} 


\section{Introduction}

Towards higher efficiencies and lower emissions, modern engines are being designed to operate in throttleless, direct-injection, and compression-ignition modes. Depending on the injection timing, the ignition and combustion occur in the homogeneous charge compression ignition (HCCI) [3] to partially premixed combustion (PPC) modes [4-7]. In these engines, autoignition of the reactant mixture plays the key role in determining the start and duration of the combustion process.[8-10]. In typical engine conditions, the autoignition process is controlled by the low-temperature oxidation of hydrocarbons [11] and detailed kinetic models have been developed to predict the ignition of the major components of liquid fuels [1214]. The key chemical pathways for low temperature oxidation of hydrocarbons have been studied since 1960s [15, 16], and more comprehensive and sophisticated mechanisms have since been developed by Westbrook and co-workers by systematically building reaction classes following specific rate rules [2, 12, 17-23]. This framework has further evolved into automatic generation of kinetic models [24, 25], semi-detailed models [26-29], and model optimization [30-33].

The low-temperature ignition reaction mechanism primarily involves two stages of sequential $\mathrm{O}_{2}$ addition which produces keto-hydroperoxides as the main chain-branching intermediates. Additional chain propagation pathways (via cyclic ethers) and chain termination pathways (via concerted $\mathrm{HO}_{2}$ eliminations) compete with the main chain branching pathway (via keto - hydroperoxides), and thereby alter the ignition timing. However, Wang et al. [1, 34] recently observed additional radical chain-branching intermediates in the low-temperature oxidation of alkanes, and proposed a third sequential $\mathrm{O}_{2}$ addition reaction scheme. The new proposed reaction mechanism applied to n-hexane mixtures predicted the formation of the additional radical chain-branching intermediates [1], which are found to promote the autoignition and advance the combustion phasing of HCCI engines at lower temperatures (e.g., 500-700 K)[35]. The promotion of autoignition from the new reaction scheme was also observed in simulations of 2-methylhexane ignition [1].

These studies clearly demonstrated that the third sequential $\mathrm{O}_{2}$ addition reaction pathways alter the ignition process significantly. However, identifying important reactions and their relation to the dynamical behavior of the complex autoignition process is challenging when using common tools such as sensitivity and reaction flux analysis techniques $[36,37]$. Sensitivity and reaction flux analysis can both assess the influence of each reaction in altering the simulated process. For instance, Zhang et al. identified QOOH $+\mathrm{O}_{2} \rightarrow$ $\mathrm{O}_{2} \mathrm{QOOH}$ and $\mathrm{H}_{2} \mathrm{O}_{2}(+\mathrm{M}) \rightarrow 2 \mathrm{OH}(+\mathrm{M})$ as the most significant reactions in the low temperature ignition of n-hexane, by using brute force sensitivity analysis [2]. However, both sensitivity and reaction flux analysis cannot assess the temporal evolution of the influence of each reaction to the dynamic modes that are responsible for autoignition [38, 39]. In addition, they cannot assess the influence of the species to the autoignition dynamics. In this work, the computational singular perturbation (CSP) methodology was adopted in order to explore the dynamics of n-hexane ignition in an ideal reactor (i.e., homogenous batch reactor) and in a simulated HCCI engine. The CSP algorithm belongs to the class of model reduction methods that are based on the multi-scale character of the model of interest [40, 41]. CSP allows for the identification of the fast and slow dynamics in the mathematical model and for the construction of the reduced model that governs the slow evolution, within the constraints 
imposed by the exhausted fast time scales [42-44]. The availability of a reduced model allows for the identification of the reactions that generate the slow time scales that characterize the slow dynamics [45-47]. Of particular interest is the case where a characteristic slow time scale relates to reactions that lead the system away from equilibrium. Such a time scale is referred as explosive [48] in the earlier analysis based on the singular perturbation theory $[49,50]$. With the advances in modern computational algorithms which can incorporate a large size of the detailed chemical kinetics mechanism of interest, the influence of the explosive time scale has been investigated in homogeneous [38, 51-56], non-homogeneous systems [51, 57-60], as well as its effects on the ignition delay [39, 52, 61].

Two kinetic models of $n$-hexane oxidation were adopted in this work: the original detailed model without third sequential $\mathrm{O}_{2}$ addition reactions by Zhang et al. [2] and the model with third sequential $\mathrm{O}_{2}$ addition reactions by Wang et al. [35]. We note that no experimental results for the third $\mathrm{O}_{2}$ addition pathways in n-hexane auto-oxidation have been reported in the literature. However, in their recent experimental work, Wang et al. observed the production of intermediates related to the third $\mathrm{O}_{2}$ addition pathways, during both the JSR oxidation of n-heptane and the partial oxidation of n-heptane in a Cooperative Fuel Research (CFR) Engine [62].

Algorithmic tools derived from the CSP methodology were used first in order to elucidate how the third sequential $\mathrm{O}_{2}$ addition reaction pathways promote n-hexane auto-oxidation in an ideal reactor (i.e., homogenous batch reactor) [35]. Homogenous batch reactors, such as shock tubes and rapid compression machines, have been widely used to study the ignition properties of fuels under conditions relevant to internal combustion engines. Since the third sequential $\mathrm{O}_{2}$ addition reaction scheme was only recently proposed, the effect of combustion conditions such as pressure, temperature, and equivalence ratio is unclear on their importance to the mechanism. To this end, the typical pressure for gasoline engine (e.g., 20 bar) and diesel engine (e.g., 60 bar) combustion, the typical temperature of cool flame (e.g., 600 and $750 \mathrm{~K}$ ), and the typical equivalence ratio of gasoline engine combustion (e.g., 1.0) and HCCI engine combustion (e.g., 0.4) were chosen. The analysis shows that the third sequential $\mathrm{O}_{2}$ addition reactions are most effective at higher pressure, lower temperature and lean combustion conditions. CSP tools were utilized to investigate the role of the third sequential $\mathrm{O}_{2}$ addition reactions under the stoichiometric fuel/air condition, which is representative of the end-gas autoignition (i.e., knock) in spark ignition engines. As shown later, stoichiometric fuel/air conditions are characterized by a single-stage ignition process, wherein the decomposition of keto-dihydroperoxides, additional radical chain-branching intermediates from the third sequential $\mathrm{O}_{2}$ addition, and the $\mathrm{O}_{2}$ addition to $\mathrm{P}(\mathrm{OOH})_{2}$ radicals (i.e., the third sequential $\mathrm{O}_{2}$ addition) play a significant role in promoting ignition delay.

In addition, CSP tools were also used in order to elucidate how the third sequential $\mathrm{O}_{2}$ addition reaction pathways advance n-hexane combustion phasing in HCCI engines [35]. Specifically, a mixture of n-hexane $/ 21 \% \mathrm{O}_{2} / 79 \% \mathrm{~N}_{2}$ at an intake pressure of $1 \mathrm{~atm}$, intake temperature of $336 \mathrm{~K}$, and equivalence ratio of 0.4 was chosen as a typical HCCI engine case. These simulations differ from those under batch reactor conditions, as the leaner conditions and compression/expansion process result in a two-stage ignition process. This permits us to study how the third sequential $\mathrm{O}_{2}$ addition reaction pathways affect low temperature heat release (LTHR) and high temperature heat release (HTHR). The results show that the decomposition of keto-dihydroperoxides and the $\mathrm{O}_{2}$ addition to $\mathrm{P}(\mathrm{OOH})_{2}$ radicals promote the 
first stage ignition, which further advances the second stage ignition.

The manuscript is structured as follows. First, a brief summary of the CSP tools employed will be given. Subsequently, details of the two chemical kinetic mechanisms under study will

be described. The discussion of the results related to the autoignition in (i) a constant volume reactor and (ii) a variable volume HCCI engine will follow.

\section{The computational singular perturbation (CSP) tools}

Consider the reaction-transport equation in the form:

$$
\frac{d \mathbf{z}}{d t}=\mathbf{L}(\mathbf{z})+\mathbf{g}(\mathbf{z})
$$

where $\mathbf{z}$ is a $N+1$-dimensional column vector that includes the $N$-dimensional column vector of the species mass fractions and the temperature $\mathbf{z}=[\mathbf{y}, T]^{T}, \mathbf{L}(\mathbf{z})$ represents the convection and diffusion differential operators and $\mathbf{g}(\mathbf{z})$ represents the chemical reaction term. This equation is cast in the CSP form:

$$
\frac{d \mathbf{z}}{d t}=\sum_{n=1}^{N+1} \mathbf{a}_{n} f^{n} \quad f^{n}=\mathbf{b}^{n} .[\mathbf{L}(\mathbf{z})+\mathbf{g}(\mathbf{z})]
$$

where $\mathbf{a}_{n}$ is the $(N+1)$-dimensional CSP column basis vector of the $n$-th mode, $f^{n}$ is the related amplitude and $\mathbf{b}^{n}$ is the corresponding $(N+1)$-dim. row $\mathrm{n}$-th dual basis vector: $\mathbf{b}^{i} \cdot \mathbf{a}_{j}=\delta_{j}^{i}[42-44]$. The action of the n-th CSP mode $\mathbf{a}_{n} f^{n}$ in Eq. (2) is assessed by (i) the related characteristic time scale $\tau_{n}$ (measures the time frame of its action), (ii) its amplitude $f^{n}$ (measures the impact of its action) and (iii) the variables that relate to this mode. When the $M$ fastest time scales $\left(\tau_{1}<\cdots<\tau_{M}\right)$ of the system in Eq. (1) are exhausted, the system reduces to:

$$
f^{m} \approx 0 \quad(m=1, \ldots M) \quad \frac{d \mathbf{z}}{d t} \approx \sum_{n=M+1}^{N+1} \mathbf{a}_{n} f^{n}
$$

The algebraic $M$-dimensional system $f^{m} \approx 0$ defines a low dimensional surface, known as slow invariant manifold (SIM), on which the solution evolves. The system of ODEs in Eq. (3) governs the slow evolution on the SIM, in the absence of the $M$ fast time scales, and its dynamics is characterized by the fastest of the slow time scales $(M+1)$, when the solution evolves sufficiently far from the boundaries of the SIM [63].

In reactive processes, the fastest time scales in the dynamics of the system in Eq. (1) usually originate from the chemical kinetics term $\mathbf{g}(\mathbf{z})$ [51, 53, 60, 61, 64-68]. Considering the case when the $n$-th nonzero eigenvalue $\lambda_{n}$ of the Jacobian of $\mathbf{g}(\mathbf{z})$ is real (the extension to complex pairs is straightforward [69]), the time scales introduced by the chemical kinetics term are approximated by the relation $\tau_{n}=\left|\lambda_{n}\right|^{-1} ; n=1, \ldots N-E+1$, where $E$ is the number of elements in the chemical kinetics mechanism employed. When $\lambda_{n}$ is positive (negative), the related time scale $\tau_{n}$ is an explosive (dissipative) one, since it relates to components of the system that tend to deviate from (approaches) equilibrium. The eigenvalue is defined as $\lambda_{n}=\boldsymbol{\beta}^{n} \cdot \mathbf{J} \cdot \boldsymbol{\alpha}_{n}$, where $\boldsymbol{\alpha}_{n}$ and $\boldsymbol{\beta}^{n}$ are the $n$-th right (column) and left (row) eigenvectors of $\mathbf{J}$, respectively; $\mathbf{J}$ being the jacobian of $\mathbf{g}(\mathbf{z})$. Assuming $K$ reversible reactions 
in the kinetics mechanism and considering their forward and backward directions separately, the $n$-th eigenvalue can be expressed as:

$$
\lambda_{n}=\boldsymbol{\beta}^{n} \cdot \sum_{k=1}^{2 K} \operatorname{grad}\left(\hat{\mathbf{S}}_{k} R^{k}\right) \cdot \boldsymbol{\alpha}_{n}=c_{1}^{n}+\ldots+c_{2 K}^{n}
$$

since $\mathbf{g}=\hat{\mathbf{S}}_{1} R^{1}+\cdots+\hat{\mathbf{S}}_{2 K} R^{2 K}$ and $\mathbf{J}=\operatorname{grad}\left(\hat{\mathbf{S}}_{1} R^{1}\right)+\cdots+\operatorname{grad}\left(\hat{\mathbf{S}}_{2 K} R^{2 K}\right)$, where $\hat{\mathbf{S}}_{n}$ and $R^{n}$ are the generalized stoichiometric vector and rate of the $\mathrm{n}$-th unidirectional reaction, respectively [38, 45]. The expression in Eq. (4) suggests the introduction of the time-scale participation index (TPI):

$$
J_{k}^{n}=\frac{c_{k}^{n}}{\left|c_{1}^{n}\right|+\ldots+\left|c_{2 K}^{n}\right|}
$$

where $n=1, \ldots N-E+1, k=1, \ldots 2 K$ and by definition $\sum_{k=1}^{2 K}\left|J_{k}^{n}\right|=1$ [45]. $J_{k}^{n}$ measures the relative contribution of the $k$-th reaction to $\lambda_{n}$ and, therefore, to $\tau_{n}$. A positive (negative) $J_{k}^{n}$ implies that the $k$-th reaction contributes to the explosive (dissipative) character of the $n$-th time scale $\tau_{n}$. The use of the TPI of the explosive mode has been used successfully in a variety of combustion and biological problems in accurately identifying the dominant chemical processes [38, 39, 46, 53, 55, 56, 61, 68, 70-73].

The adiabatic ignition of a homogeneous mixture in engine-relevant conditions is governed by the species and temperature equations:

$$
\frac{d}{d t}\left[\begin{array}{c}
\mathbf{y} \\
T
\end{array}\right]=\frac{1}{\rho}\left[\begin{array}{c}
\mathbf{W} \\
\frac{1}{c_{v}}\left(-\mathbf{h}_{c} \cdot \mathbf{W}+R T \mathbf{U}\right)
\end{array}\right] \cdot \sum_{k=1}^{2 K} \mathbf{S}_{k} R^{k}+\left[\begin{array}{c}
0 \\
-1
\end{array}\right] \frac{1}{\rho c_{v}} \frac{P}{V} \frac{d V}{d t}
$$

where $\rho$ is the mixture density, $\mathbf{W}$ is a $N \times N$ diagonal matrix with the species molecular weights in the diagonal, $c_{v}$ is the specific heat under constant volume, $\mathbf{h}_{c}$ is the $N$-dimensional vector of the species absolute enthalpies, $R$ is the universal gas constant, $T$ is the temperature, $\mathbf{U}=[1, \ldots, 1], \mathbf{S}_{k}$ and $R^{k}$ represent the stoichiometric vector and reaction rate, respectively, of the $k$-th unidirectional reaction, $P$ is the pressure and $V$ is the volume. The two directions of the $K$ reversible reactions are considered separately in Eq. (6), in order to assess the influence of each direction. The last term in Eq. (6) represents the effect of variable volume and is absent in the isochoric case. The volume rate of change is calculated in terms of the crank angle by the relation [74]:

$$
\frac{d V}{d t}=\Omega\left(\frac{C-1}{2}\right) \cdot \sin \theta \cdot\left(1+\frac{\cos \theta}{\sqrt{R^{2}-\sin ^{2} \theta}}\right) \cdot V_{C}
$$

where $\Omega$ is the rotational speed of the crank arm in degrees per second:

$$
\Omega=2 \pi \frac{r p m}{60}
$$

and rpm is the engine speed, $C$ is the engine compression ratio, $\theta$ is the angle of the crank arm, $R$ is the engine connecting rod to crank radius ratio, and $V_{C}$ is the clearance volume calculated through the following relation:

$$
V_{C}=\frac{V_{s, \max }}{C-1}
$$


where $\mathrm{V}_{s, \max }$ is the engine cylinder displacement volume. Finally, $\theta$ is the angle of the connecting rod:

$$
\theta=\Omega \cdot t+C A D_{I V C}
$$

where $t$ stands for time and $C A D_{I V C}$ is the starting crank angle at the intake valve closure $(\mathrm{t}=0)$.

\section{Chemical kinetics models}

Two kinetic models of n-hexane oxidation were adopted in the 0 -D autoignition and HCCI simulations, taken from Zhang et al. [2] and Wang et al. [35]. The former, referred to as the C6 model, was developed by including significant updates to thermochemical group values, alternative isomerization reaction pathways and quantum chemically derived rate rules. The kinetic model was refined and tested against ignition delay times over a wide range of temperature and pressure against experimental speciation data obtained in a high-pressure jet-stirred reactor. The latter, referred to as the extended C6 model, was developed by including the third sequential $\mathrm{O}_{2}$ addition reactions for selected $\mathrm{P}(\mathrm{OOH})_{2}$ radicals based on the Zhang model. Subsequent pathways involve internal H-atom migration of $\mathrm{OOP}(\mathrm{OOH})_{2}$ to keto-dihydroperoxide (KDHP) and/or dihydroperoxy cyclic ether (DHPCE), and concerted eliminations of $\mathrm{OOP}(\mathrm{OOH})_{2}$ to $\mathrm{HO}_{2}$ and olefinic dihydroperoxides (ODHP). Hydrogen abstraction from KDHP and DHPCE, and subsequent decomposition of the intermediate radicals to diketo-hydroperoxide (DKHP) and keto-hydroperoxy cyclic ether (KHPCE) were also included. The decomposition of intermediate species (KDHP, DHPCE, ODHP, DKHP, and $\mathrm{KHPCE}$ ) formed via the third sequential $\mathrm{O}_{2}$ addition processes were treated analogously to those of ketohydroperoxides (KHP) in the original C6 model.

The $\mathrm{C} 6$ model consists of $\mathrm{N}=1118$ species, $\mathrm{E}=6$ elements $(\mathrm{O}, \mathrm{H}, \mathrm{C}, \mathrm{N}, \mathrm{He}, \mathrm{Ar}$ ) and $\mathrm{K}=4808$ reversible reactions, while the extended $\mathrm{C} 6$ model (which includes additional $\mathrm{O}_{2}$ reactions) consists of $\mathrm{N}=1188$ species, $\mathrm{E}=6$ elements $(\mathrm{O}, \mathrm{H}, \mathrm{C}, \mathrm{N}, \mathrm{He}, \mathrm{Ar})$ and $\mathrm{K}=4959$ reversible reactions. In the following discussion, subscripts " $\mathrm{f}$ " and " $\mathrm{b}$ " in the reactions denote forward and backward directions, respectively.

\section{Results}

\subsection{Autoignition in a Constant Volume Reactor}

The adiabatic homogeneous isochoric autoignition of an n-hexane/air mixture was first studied at various initial temperature, pressure, and equivalence ratio conditions. The objective was to determine the conditions at which the two chemical kinetic models differ the most and then to select these conditions in order to identify the dominant chemical processes that determine the dynamics of the system [2, 35].

The ignition delay time $t_{\text {ign }}$ computed at various initial conditions is displayed in Table 1. It is shown that the ignition delay time provided by the two mechanisms differs significantly at low initial temperatures $(\mathrm{T}(0)=600 \mathrm{~K})(\min 39 \%$ and $\max 46 \%)$, regardless of the initial pressure $(\mathrm{p}(0)=20$ and $60 \mathrm{~atm})$ or the stoichiometry $(\phi=0.4$ and 1$)$ of the system. At intermediate initial temperatures $(\mathrm{T}(0)=750 \mathrm{~K})$, however, these differences are mitigated ( $\min 7 \%$ and $\max 17 \%$ ). These findings suggest that it is mainly the low temperature radical chain branching chemistry that is different between the kinetic models. In particular, 
the third sequential $\mathrm{O}_{2}$ addition reaction pathways are favored at: (i) lower temperatures because the intermediate $\mathrm{OOP}(\mathrm{OOH})_{2}$ peroxy radical is thermodynamically more stable, (ii) higher pressures because the bimolecular reaction of $\left.\left.\mathrm{O}_{2}+\mathrm{P}(\mathrm{OOH})_{2}\right)=\mathrm{OOP}(\mathrm{OOH})_{2}\right)$ is thermodynamically favored, and (iii) lean equivalence ratios because the $\mathrm{O}_{2}$ concentration is higher.

Table 1: The ignition delay times of the the two mechanisms ( $\mathrm{C} 6$ and extended $\mathrm{C} 6$ ) at various initial conditions; i.e., $\mathrm{p}(0), \mathrm{T}(0)$ and $\phi$. The last column displays the relative difference of the ignition delay times between the two mechanisms.

\begin{tabular}{cccccc}
\hline $\mathrm{p}(0)[\mathrm{atm}]$ & $\mathrm{T}(0)[\mathrm{K}]$ & $\phi$ & \multicolumn{2}{c}{$\mathrm{t}_{\text {ign }}[\mathrm{s}]$} & \% change \\
& & & $\mathrm{C} 6$ & extended $\mathrm{C} 6$ & \\
\hline 20 & 600 & 0.4 & $2.396 \mathrm{E}-01$ & $1.390 \mathrm{E}-01$ & $-41.99 \%$ \\
20 & 600 & 1 & $2.031 \mathrm{E}-01$ & $1.242 \mathrm{E}-01$ & $-38.85 \%$ \\
\hline 20 & 750 & 0.4 & $3.492 \mathrm{E}-03$ & $3.232 \mathrm{E}-03$ & $-7.45 \%$ \\
20 & 750 & 1 & $1.810 \mathrm{E}-03$ & $1.642 \mathrm{E}-03$ & $-9.28 \%$ \\
\hline 60 & 600 & 0.4 & $1.809 \mathrm{E}-01$ & $9.765 \mathrm{E}-02$ & $-46.02 \%$ \\
60 & 600 & 1 & $1.491 \mathrm{E}-01$ & $8.610 \mathrm{E}-02$ & $-42.25 \%$ \\
\hline 60 & 750 & 0.4 & $1.174 \mathrm{E}-03$ & $9.720 \mathrm{E}-04$ & $-17.21 \%$ \\
60 & 750 & 1 & $9.200 \mathrm{E}-04$ & $7.630 \mathrm{E}-04$ & $-17.07 \%$ \\
\hline
\end{tabular}

CSP diagnostics were obtained for all cases of initial conditions in Table 1. For brevity, the results of only one case is presented here: $T(0)=600 \mathrm{~K}, p(0)=60 \mathrm{~atm}$ and $\phi=1$ (reference case). This is the case for which the second maximum difference in $t_{\text {ign }}$ between the two mechanisms is observed. Results for the TPI for the fastest explosive time scale, say $\tau_{e, f}$, in the dynamics of the system will be presented. This time scale relates directly to $t_{i g n}$, so the TPI index will identify the reactions that influence the ignition dynamics through their contribution to the generation of $\tau_{e, f}[38,39]$. The development of an explosive time scale is a necessity for the autoignition of homogeneous mixtures and might be encountered in flames; see Ref. [38] and the references listed herein.
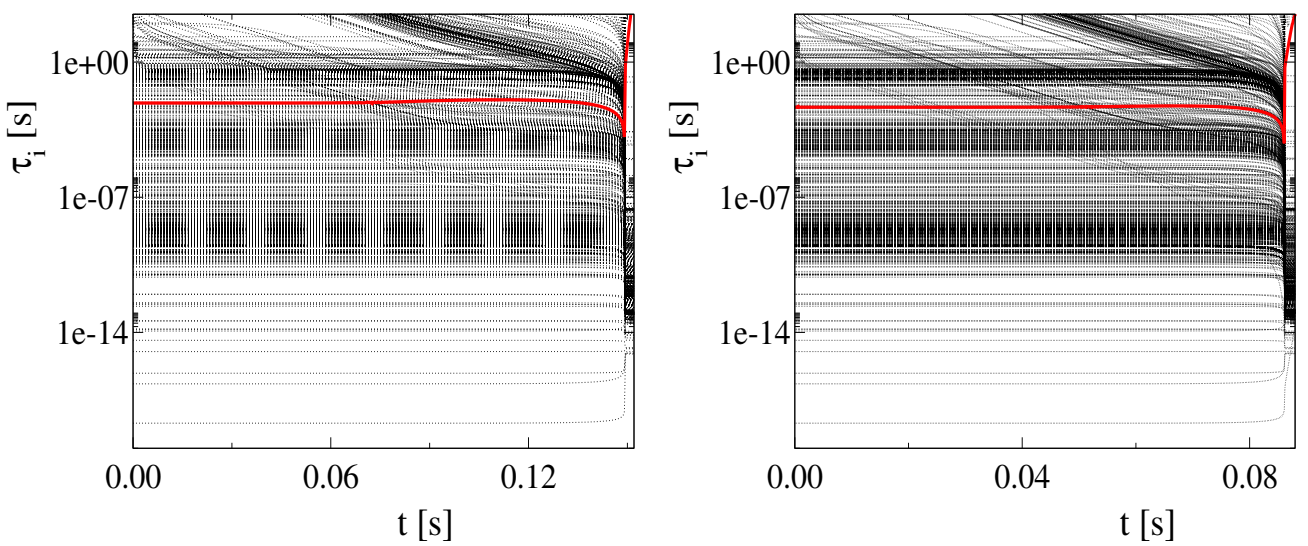

Figure 1: The developing time scales during autoignition of the two hexane mechanisms; C6 (left) and extended C6 (right). Solid and dotted lines represent explosive and dissipative time scales, respectively; $T(0)=600 \mathrm{~K}, p(0)=60$ atm, $\phi=1$.

The time scales that characterise the dynamics of the process at the reference case for both the C6 and the extended C6 mechanisms are illustrated in Fig. 1. For both mechanisms, 
all time scales are dissipative (i.e., they characterise processes which tend to drive the system to equilibrium) except for two time scales, which are explosive (i.e., they characterise processes that tend to drive the system away from equilibrium). The period during which these explosive time scales are present was introduced as the explosive stage of the autoignition process [38].

The fastest of the explosive time scales $\tau_{e, f}$ appears from the start of the process and remains constant for the most part of the explosive stage. At the end of this stage $\tau_{e, f}$ accelerates (when the $\mathrm{H}_{2} / \mathrm{O}_{2}$ chemistry dominates its development), then decelerates and merges with the slow explosive time scale $\tau_{e, s}$. When the two explosive time scales merge, they disappear and the explosive stage comes to an end. The direct relation of $\tau_{e, f}$ to $t_{i g n}$ is manifested by the similarity of the ratio of the two $\tau_{e, f}$ in the cases of the extended C6 and of C6 (computed at $\mathrm{t}=t_{i g n} / 2$ ) is similar to the ratio of the corresponding $t_{i g n}$; i.e. $\tau_{e, f-(C 6 e x t)} / \tau_{e, f-(C 6)}=0.576$ and $t_{i g n-(C 6 e x t)} / t_{i g n-(C 6)}=0.577$.

In a fully nonlinear ignition model, $\tau_{e, f}$ relates to a mode among the fastest of the slow (non-exhausted) ones and thus appears slightly above the gap between the slow (active) and fast (exhausted) time scales. Such a feature is conventionally required, in order for $\tau_{e, f}$ to be characteristic of the slow system that governs the process when the $\mathrm{M}$ fastest time scales become exhausted. However, due to the quasi-linear character of the dynamics (as manifested by the constancy of all fastest time scales including $\tau_{e, f}$ ), the analysis of the fast explosive timescale $\tau_{e, f}$ as the main driving mode remains valid in cases where such a fast/slow gap does not develop. Similar behaviour was found in the autoignition of DME/air mixtures [39]. The significance of $\tau_{e, f}$ as the driving mode for the ignition of the system is also manifested by the magnitude of its amplitude, which is the largest in both cases throughout the explosive stage.
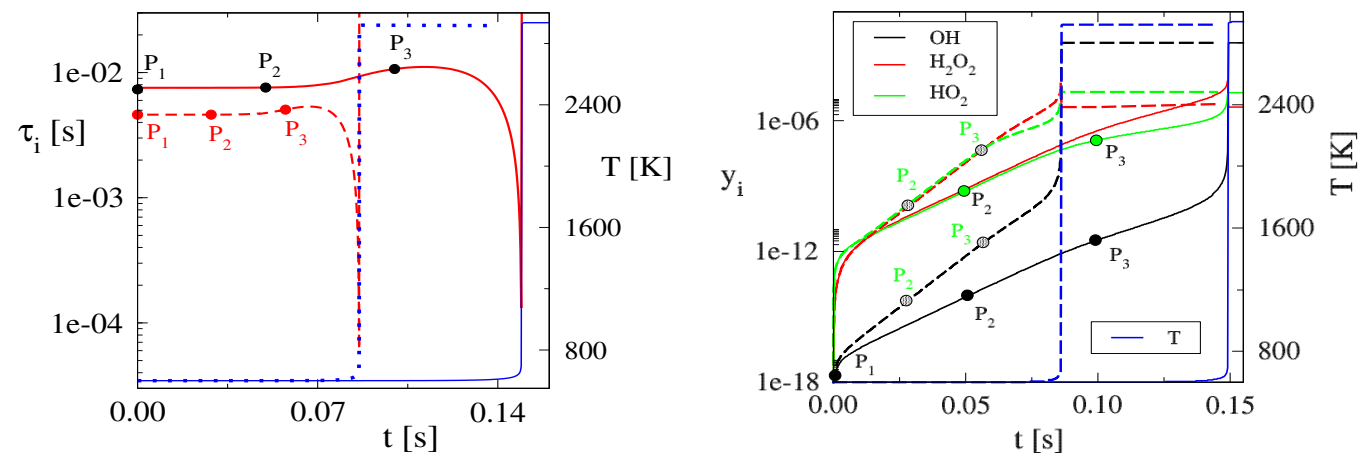

Figure 2: Left: The developing explosive time scales and the temperature evolution during autoignition of the two hexane mechanisms. Right: The evolution of $\mathrm{OH}, \mathrm{H}_{2} \mathrm{O}_{2}, \mathrm{HO}_{2}$ and temperature for the two mechanisms. Both left and right: $\mathrm{p}(0)=60 \mathrm{~atm}, \phi=1$ and $\mathrm{T}(0)=600 \mathrm{~K}$; C6 (solid lines) and extended C6 (dashed lines). $\mathrm{P}_{1}$ to $\mathrm{P}_{3}$ indicate the points at which the CSP diagnostics displayed in Table 3 were computed.

The evolution of the fast explosive time scale $\tau_{e, f}$ that develops in the reference case is displayed in Fig. 2. Throughout the explosive stage, $\tau_{e, f}$ of the extended C6 kinetics mechanism (4959 reactions) has a smaller value than that of the C6 mechanism (4808 reactions), thus resulting in a smaller $t_{i g n}$. Fig. 2 also shows the time evolution of temperature and concentrations of the $\mathrm{OH}, \mathrm{HO}_{2}$ and $\mathrm{H}_{2} \mathrm{O}_{2}$ radicals, which are important species controlling 
the ignition process $[75,76]$. It is shown that the radical build-up, which leads to ignition, is accelerated with the extended C6 mechanism.

The roles of the individual elementary reactions during the explosive stage was examined in details at three indicative points of the process, $\mathrm{P}_{1}$ to $\mathrm{P}_{3}$, which are marked in Fig. 2;. $\mathrm{P}_{1}$ $(\mathrm{t}=0 \mathrm{sec})$ corresponds to the initial formation of radical species, while $\mathrm{P}_{2}\left(\mathrm{t}=\mathrm{t}_{\text {ign }} / 3\right)$ and $\mathrm{P}_{3}\left(\mathrm{t}=2 \mathrm{t}_{\text {ign }} / 3\right)$ correspond to times when the radical pool is in the exponential growth phase. Note that temperature does not change significantly between these three indicative points.

Table 2: The reaction groups providing significant contribution to the generation of the fast time scale $\tau_{e, f}$, during the autoignition of the n-hexane/air mixture; $\mathrm{F}: \mathrm{nC}_{6} \mathrm{H}_{14}, \mathrm{R}$ is in ROO: $\mathrm{C}_{6} \mathrm{H}_{13}, \mathrm{Q}$ in $\mathrm{QOOH}$ and $\mathrm{O} 2 \mathrm{QOOH}: \mathrm{C}_{6} \mathrm{H}_{12}, \mathrm{Q}^{\prime}$ in $\mathrm{OQ}^{\prime}=\mathrm{O}: \mathrm{C}_{6} \mathrm{H}_{11}$, $\mathrm{P}$ in $\mathrm{P}(\mathrm{OOH}) 2: \mathrm{C}_{6} \mathrm{H}_{11}$. Reaction groups in bold are those that are included only in the extended mechanism [35].

$\begin{array}{ll}\mathrm{R}_{1} & \mathrm{R} \text { unimolecular reactions } \\ \mathrm{R}_{2} & \mathrm{~F}+\mathrm{OH} \leftrightarrow \mathrm{R}+\mathrm{H}_{2} \mathrm{O} \\ \mathrm{R}_{3} & \mathrm{~F}+\mathrm{HO}_{2} \leftrightarrow \mathrm{R}+\mathrm{H}_{2} \mathrm{O}_{2} \\ \mathrm{R}_{4} & \mathrm{RO}_{2} \leftrightarrow \mathrm{QOOH} \\ \mathrm{R}_{5} & \mathrm{RO}_{2} \leftrightarrow \text { olefin }+\mathrm{HO}_{2} \\ \mathrm{R}_{6} & \mathrm{QOOH}+\mathrm{O}_{2} \leftrightarrow \mathrm{O}_{2} \mathrm{QOOH} \\ \mathrm{R}_{7} & \mathrm{O}_{2} \mathrm{QOOH} \leftrightarrow \mathrm{KHP}+\mathrm{OH} \\ \mathrm{R}_{8} & \mathrm{O}_{2} \mathrm{QOOH} \leftrightarrow \mathrm{OHP}+\mathrm{HO}_{2} \\ \mathrm{R}_{9} & \mathrm{O}_{2} \mathrm{QOOH} \leftrightarrow \mathrm{P}(\mathrm{OOH})_{2}\end{array}$

$\begin{array}{rl}\mathrm{R}_{10} & \mathrm{P}(\mathrm{OOH})_{2} \leftrightarrow \mathrm{OHP}+\mathrm{HO}_{2} \\ \mathrm{R}_{11} & \mathrm{P}(\mathrm{OOH})_{2} \leftrightarrow \mathrm{HPCE}+\mathrm{OH} \\ \mathbf{R}_{12} & \mathrm{P}(\mathrm{OOH})_{2}+\mathrm{O}_{2} \leftrightarrow \mathrm{OOP}(\mathrm{OOH})_{2} \\ \mathbf{R}_{13} & \mathrm{OOP}(\mathrm{OOH})_{2} \leftrightarrow \mathrm{KDHP}+\mathrm{OH} \\ \mathbf{R}_{14} & \mathrm{~T}(\mathrm{OOH})_{3} \leftrightarrow \mathrm{ODHP}+\mathrm{HO}_{2} \\ \mathbf{R}_{15} & \mathrm{~T}(\mathrm{OOH})_{3} \leftrightarrow \mathrm{DHPCE}+\mathrm{OH} \\ \mathrm{R}_{16} & \mathrm{KHP} \leftrightarrow \mathrm{OQ}=\mathrm{O}+\mathrm{OH} \\ \mathrm{R}_{17} & \mathrm{HPCE} \leftrightarrow \text { products }+\mathrm{OH} \\ \mathbf{R}_{18} & \text { KDHP } \leftrightarrow \text { products }+\mathrm{OH}\end{array}$

Table 2 lists the reaction groups that contribute significantly to the generation of the fast time scale $\tau_{e, f}$. Their quantitative contributions to $\tau_{e, f}$, evaluated at the points $\mathrm{P}_{1}(\mathrm{t}=0$ sec $), \mathrm{P}_{2}\left(\mathrm{t}=\mathrm{t}_{\text {ign }} / 3\right)$ and $\mathrm{P}_{3}\left(\mathrm{t}=2 \mathrm{t}_{\text {ign }} / 3\right)$ are summarized in Table 3 , which lists the TPI values of each reaction group for both the C6 and extended C6 mechanisms for the reference case. The TPI value of each reaction group is computed by adding the related TPI values of the reactions that belong to this group.

The results displayed in the upper part of Table 3 indicate that in the case of the C6 mechanism, the dominant contribution to $\tau_{e, f}$ is produced by KHP decomposition reactions (reaction group $\mathrm{R}_{16 f}$ ), favoring the explosive character of $\tau_{e, f}$, thereby promoting the process to ignition. Additional significant positive contribution is provided by reaction $\mathrm{R}_{7 f}$, involving conversion of $\mathrm{O}_{2} \mathrm{QOOH}$ radicals to $\mathrm{KHP}$ and highly reactive $\mathrm{OH}$ radicals. These reaction steps are the primary radical chain branching pathways in n-hexane low temperature oxidation. Reactions $\mathrm{R}_{4 f}, \mathrm{R}_{3 f}, \mathrm{R}_{11 f}, \mathrm{R}_{17 f}$ and $\mathrm{R}_{6 f}$ also provide considerable positive contributions and promote ignition. The major opposition to the generation of $\tau_{e, f}$ is produced by reaction $\mathrm{R}_{10 f}$ (elimination of $\mathrm{HO}_{2}$ from $\mathrm{P}(\mathrm{OOH})_{2}$ ) and $\mathrm{R}_{4 b}$ (isomerization of QOOH into $\mathrm{RO}_{2}$ ). These latter reaction groups compete with the low temperature radical chain branching process, and therefore suppress the ignition process. Aside from minor changes in their relative magnitudes, and the slightly increased contributions from $\mathrm{R}_{8 f}$ and $\mathrm{R}_{9 f}$ to the suppression of reactivity at $\mathrm{P}_{3}\left(t=2 t_{\text {ign }} / 3\right)$, the overall chemical characteristics based on the $\mathrm{C} 6$ mechanism are consistent with conventional knowledge of hydrocarbon low temperature oxidation chemistry $[14,77]$.

We now compare the low temperature ignition characteristics based on the extended C6 mechanism, which includes approximately 150 more reactions. The TPI results for this mechanism are displayed in the lower part of Table 3 . At the beginning of the process $(t=0)$, the most significant contributors to $\tau_{e, f}$ in the extended C6 mechanisms is reaction $\mathrm{R}_{18 f}$ (decomposition of KDHP to form $\mathrm{OH}$ radical) followed by $\mathrm{R}_{16 f}$ (KHP decomposition to 
Table 3: Values of the largest TPI $\left(J_{k}^{e}\right)$ during the autoignition process of the two hexane mechanisms; C6 (upper part) and extended C6 (lower part). At each point, the values of the time scale $\tau_{e, f}$ and amplitude $f^{e, f}$ of the explosive mode are displayed. Reaction groups in bold are those that are included only in the extended C6 mechanism. Refer to Fig. 2 for the selected points $\mathrm{P}_{1}, \mathrm{P}_{2}$ and $\mathrm{P}_{3}$.

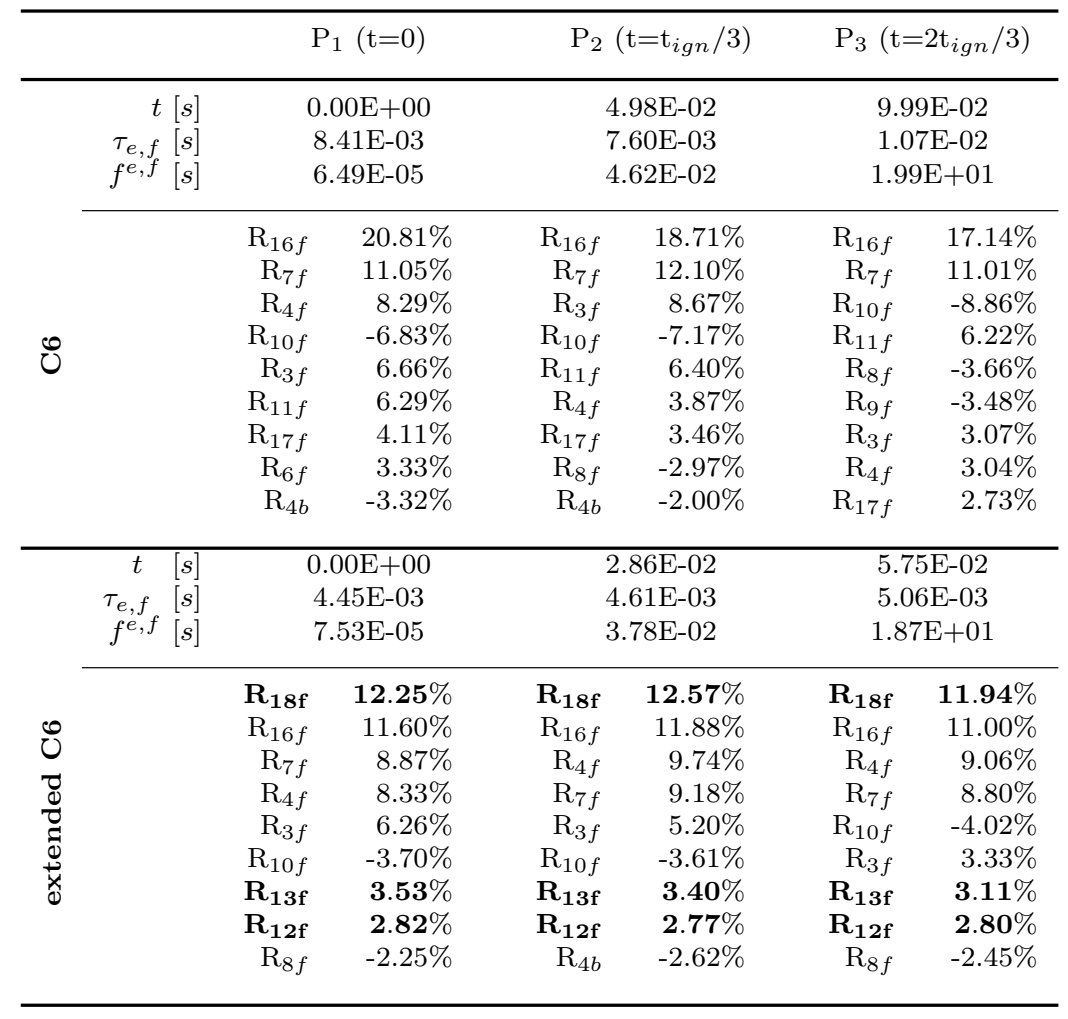

$\mathrm{OH}$ radical). Both reactions involve the decomposition of unstable intermediates to produce highly reactive $\mathrm{OH}$ radicals. Additional significant contribution favoring the explosive character of $\tau_{e, f}$ is provided by reactions $\mathrm{R}_{7 f}, \mathrm{R}_{4 f}$ and $\mathrm{R}_{3 f}$. Reaction groups $\mathrm{R}_{13 f}$ (formation of $\mathrm{KDHP}$ and $\mathrm{OH}$ radical) and $\mathrm{R}_{12 f}$ (the third $\mathrm{O}_{2}$ addition reaction) also provide some additional contribution but they are limited in driving the explosive character of $\tau_{e, f}$. The major opposition to $\tau_{e, f}$ is provided by reaction $\mathrm{R}_{10 f}$ as with the $\mathrm{C} 6$ mechanism.

As the ignition process proceeds to $t_{i g n} / 3$ and $2 t_{i g n} / 3$, the set of the most significant reaction groups and their contributions to $\tau_{e, f}$ does not change qualitatively but only quantitatively. The major positive contributors hardly change, which explains why $\tau_{e, f}$ remains essentially constant. At $2 t_{i g n} / 3$, the contribution from $\mathrm{R}_{18 f}$ decreases only slightly, while the contribution of $\mathrm{R}_{10 f}$ increases slightly in the negative (suppression) direction. The combined effect results in the increased $\tau_{e, f}$ toward the latter stage of ignition.

A comparison of the TPI results for two mechanisms, displayed in Table 3, leads to the following conclusions:

- Reactions $\mathrm{R}_{18 f}, \mathrm{R}_{13 f}$ and $\mathrm{R}_{12 f}$, which are included only in the extended $\mathrm{C} 6$ mechanism and contribute to radical chain branching, exhibit a significant influence in promoting the explosive nature of the system, with $\mathrm{R}_{18 f}$ being the dominant reaction.

- Reactions $\mathrm{R}_{16 f}, \mathrm{R}_{7 f}$ and $\mathrm{R}_{3 f}$ exhibit a significant influence in both the $\mathrm{C} 6$ and extended C6 mechanisms, promoting ignition. For both cases, their influence does not change 
significantly during the explosive stage. The former two reactions are related to the formation and destruction of KHP, which lead to $\mathrm{OH}$ radical production, while latter reactions involve production of hydrogen peroxided $\left(\mathrm{H}_{2} \mathrm{O}_{2}\right)$, which also decomposes to form $\mathrm{OH}$ radicals.

- Reaction $\mathrm{R}_{10 f}$ is the main process that suppresses the explosion of the system for both mechanisms. This reaction group leads to production of $\mathrm{HO}_{2}$ radicals, and competes directly with $\mathrm{OH}$ radical production, thereby reducing reactivity. Its influence in the explosive stage does not change significantly.

- Reactions $\mathrm{R}_{11 f}$ and $\mathrm{R}_{17 f}$ (formation and destruction of HPCE) have a notable influence towards explosiveness in the case of the $\mathrm{C} 6$ mechanism and a negligible one in the case of the extended $\mathrm{C} 6$ mechanism. These reactions are less important in the extended C6 mechanism because the $\mathrm{P}(\mathrm{OOH})_{2}$ radical intermediates have alternate pathways to drive the ignition process (i.e., via $\mathrm{R}_{12 f}, \mathrm{R}_{13 f}$, and $\mathrm{R}_{18 f}$ ). In contrast, the influence of reaction $\mathrm{R}_{4 f}$ towards ignition increases considerably in the case of the extended $\mathrm{C} 6$ mechanism.

\subsection{Autoignition in a Variable Volume HCCI Engine}

In the constant volume autoignition simulation under the selected conditions, only a single stage ignition event was observed. However, hydrocarbon fuels typically display twostage ignition characteristics. Under HCCI engine conditions, it is common to observe a low temperature heat release (LTHR) that relates to a first-stage ignition delay time, followed by a high temperature heat release (HTHR) that relates to the second-stage ignition delay time [78]. The investigation of the influence exerted by the various reactions under HCCI engine conditions can provide further insights into the contributions by the third sequential $\mathrm{O}_{2}$ addition reactions to LTHR and HTHR at the first and second stage ignition delay events, respectively.

The ignition of n-hexane/air mixture in HCCI environment was investigated using the $\mathrm{C} 6$ and extended $\mathrm{C} 6$ chemical kinetics mechanisms [2, 35]. The code Chemkin-PRO was used in order to solve the system of Eqs. 6 and 7, using an adiabatic single-zone HCCI engine model. The input for the HCCI engine simulation was the same as that in Ref. [35], e.g., a mixture of n-hexane/air at an intake pressure $\mathrm{p}(0)$ of $1 \mathrm{~atm}$, intake temperature $\mathrm{T}(0)$ of $336 \mathrm{~K}$, and equivalence ratio $\phi$ of 0.4. A total duration of 190 engine crank angle degrees were simulated with an engine compression ratio $C$ of 12 , engine speed of $1650 \mathrm{rpm}$, engine cylinder displacement volume $\mathrm{V}_{s, \max }$ of $474 \mathrm{~cm}^{3}$, engine connecting rod to crank radius ratio $R$ of 2.5 , and starting crank angle $C A D_{I V C}$ of -142.5 degrees.

Fig. 3 presents the evolution of the explosive timescales for the $\mathrm{C} 6$ and extended $\mathrm{C} 6$ mechanisms, along with the respective evolution of temperature. The temperature evolution clearly exhibits a 2 -step ignition process, and the accompanying time scales show that the two ignition stages are characterized by distinct sets of explosive timescales $\tau_{e}$. Specifically, at the start of the process an explosive timescale $\tau_{e, f}$ emerges and continuously accelerates, until it merges with a slower explosive timescale to disappear. The disappearance of the explosive timescales coincides with the first stage ignition of the process. In fact, the left panel of Fig. 3 shows that when the explosive timescales disappear, the temperature rises to half of the total first stage increase. 

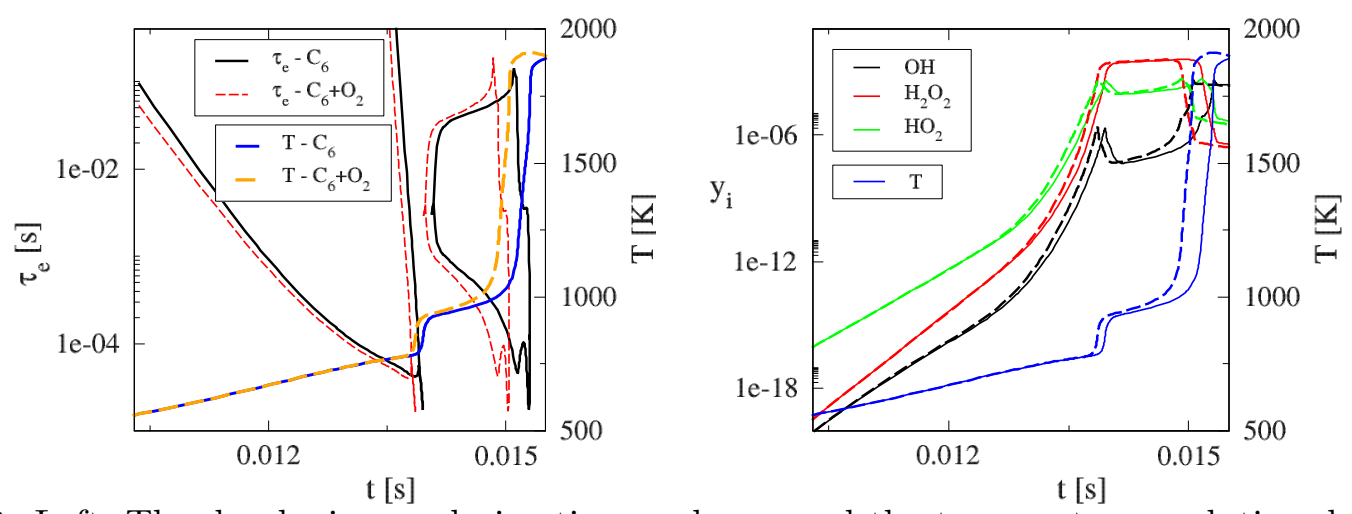

Figure 3: Left: The developing explosive time scales $\tau_{e}$ and the temperature evolution during the HCCI. Right: the evolution of the mass fractions of $\mathrm{OH}, \mathrm{H}_{2} \mathrm{O}_{2}$ and $\mathrm{HO}_{2}$ and of T. Both left and right: C6 (solid lines) and extended C6 (dashed lines); $\mathrm{p}(0)=1 \mathrm{~atm}, \phi=0.4$ and $\mathrm{T}(0)=336 \mathrm{~K}$.

After the completion of the first stage ignition, a new set of explosive timescales emerges: a fast one $\tau_{e, f}$ which is accelerating and a slow one $\tau_{e, s}$ which is decelerating. As will be shown next, this second stage is highly related to the thermal character of the system. The fast explosive timescale, which is the characteristic time scale of the system in that period, accelerates until it reaches a local minimum, then decelerates for a brief period. It subsequently starts a rapid acceleration followed by a deceleration again, before it finally merges with the slow explosive timescale to disappear. The disappearance of both explosive timescales determines the end of the explosive stage. At that point, the temperature of the system has risen sufficiently, and ultimately reaches its maximum value.

Comparing the fast explosive timescales $\tau_{e, f}$ of both mechanisms, $\tau_{e, f}$ in the case of the extended C6 mechanism is always faster than that of C6 mechanism. This explains why the extended C6 mechanism attains a shorter ignition delay time. Although the difference of $\tau_{e, f}$ between the two mechanisms appears more pronounced in the second rather than in the first stage, it is the first stage that relates to the chemical runaway of the process, and therefore it determines the evolution of the second stage that follows. This is discussed in further detail below.

To investigate the dependance of the system on temperature, the initial full $(\mathrm{N}+1) \mathrm{x}$ $(\mathrm{N}+1)$ Jacobian of the system is truncated by eliminating the column and row, which relate to the temperature variable. This is a practice that has been successfully used in the past to identify the chemical/thermal runaway regimes of various fuels $[38,61,73]$. 

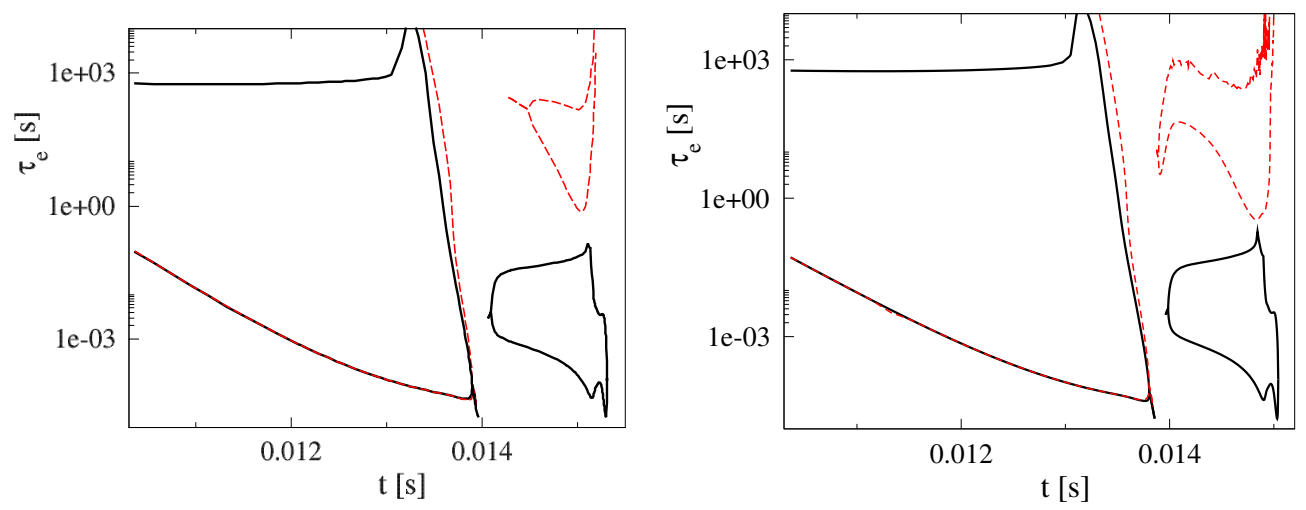

Figure 4: The developing explosive time scales of the full (solid lines) and the truncated (dashed lines) Jacobians during the HCCI of the two hexane mechanisms; C6 (left) and extended C6 (right); $\mathrm{p}(0)=1$ atm, $\phi=0.4$ and $\mathrm{T}(0)=336 \mathrm{~K}$.

The explosive timescales $\tau_{e}$ calculated from the $\mathrm{N}$ x $\mathrm{N}$ truncated Jacobian are displayed with dashed lines in Fig. 4. It is shown that the fast explosive timescales $\tau_{e, f}$ in both mechanisms calculated from the truncated Jacobians have the same values with the fast explosive timescales $\tau_{e, f}$ computed from the full Jacobians, during the first stage ignition. This means that the dependence of the systems to temperature is weak during the first stage ignition. On the other hand, this dependence is much stronger during the second stage, such that the fast explosive timescales $\tau_{e, f}$ of the truncated Jacobians differ significantly from the respective timescales of the full Jacobians. Therefore, it is concluded that the first stage ignition is in the chemical runaway regime, while the second stage ignition is in the thermal runaway regime.

\subsubsection{First-stage ignition}

To investigate the dominant chemistry leading to ignition, CSP diagnostics (TPI) results were generated for both mechanisms at selected points in time. The first 3 points $\left(\mathrm{P}_{1}\right.$ to $\left.\mathrm{P}_{3}\right)$, shown in Fig. 5, relate to the first-stage ignition. The TPI values for $\tau_{e, f}$ at these three points, computed on the basis of the C6 and extended C6 mechanisms, are shown in Table 4 (C6 on the top, extended C6 on the bottom). The values of $\tau_{e, f}$ displayed are in accordance with the findings shown in Fig. 4; i.e., that the first stage process is faster when considering the extended C6 mechanism. In addition, Table 4 suggests that the impact of the fast explosive mode is stronger in that case, as it is indicated by the values of the related amplitude $f_{e, f}$ (especially at $\mathrm{P}_{3}$ ).

Considering the $\mathrm{C} 6$ mechanism, Table 4 shows that at point $\mathrm{P}_{1}$ the dominant contributor to $\tau_{e, f}$ is reaction $\mathrm{R}_{16 f}$, promoting the explosive character of $\tau_{e, f}$. Additional similar contributions are provided by reactions $\mathrm{R}_{7 f}, \mathrm{R}_{6 f}, \mathrm{R}_{11 f}$ and $\mathrm{R}_{4 f}$. The most significant opposition to the generation of $\tau_{e, f}$ is provided by reactions $\mathrm{R}_{10 f}$ and $\mathrm{R}_{4 b}$. Additional but less significant opposing contributions are provided by reactions $\mathrm{R}_{9 f}, \mathrm{R}_{5 f}$ and $\mathrm{R}_{8 f}$. In general, the set of dominant contributors to $\tau_{e, f}$ at point $\mathrm{P}_{1}$ is similar in both the constant volume ignition and HCCI engine ignition cases.

As time progresses in the period that leads to the first stage ignition (points $\mathrm{P}_{2}$ and $\mathrm{P}_{3}$ ), the following changes are noted for the major chemical processes in terms of their contributions to $\tau_{e, f}$ : 

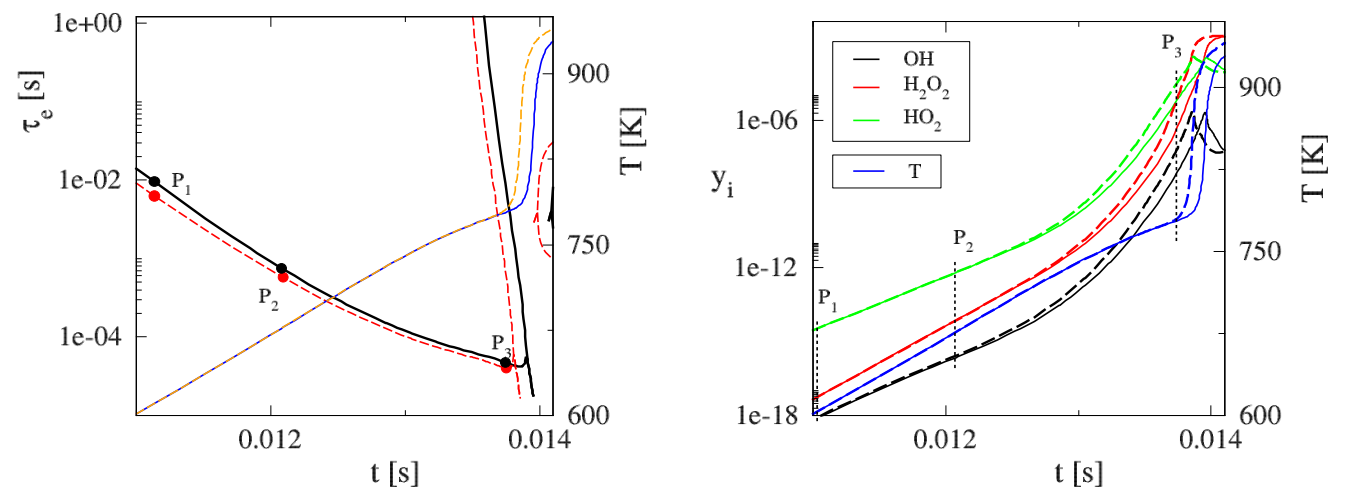

Figure 5: Left: The evolution of the explosive timescales and temperature during the 1st stage ignition. $\mathrm{P}_{1}-\mathrm{P}_{3}$ represent points at which CSP diagnostics for $\tau_{e, f}$ were generated. Right: The evolution of the species mass fractions of $\mathrm{OH}, \mathrm{H}_{2} \mathrm{O}_{2}, \mathrm{HO}_{2}$ and of $\mathrm{T}$ during the 1st stage ignition. Both left and right: $\mathrm{C} 6$ (solid lines) and extended $\mathrm{C} 6$ (dashed lines); $\mathrm{p}(0)=1 \mathrm{~atm}, \phi=0.4$ and $\mathrm{T}(0)=336 \mathrm{~K}$.

- Reaction $\mathrm{R}_{16 f}$ remains the major contributor to the generation of $\tau_{e, f}$, favoring its explosive character, but its influence decreases at the final part of the first stage ignition. This is due to the rising temperature during the first stage ignition process, so that at point $\mathrm{P}_{3}$ the KHP species in $\mathrm{R}_{16 f}$ are no longer stable. They contribute significantly to $\mathrm{OH}$ radical build-up in the early parts of the ignition process, but are less important once the temperature increases above approximately $700 \mathrm{~K}$.

- The positive effect (favoring the explosive character of $\tau_{e, f}$ ) of reactions $\mathrm{R}_{7 f}$ and $\mathrm{R}_{11 f}$ decreases with time while that of reactions $\mathrm{R}_{6 f}$ and $\mathrm{R}_{4 f}$ increases. The former set of reactions lead to the formation of chain branching intermediates (KHP and HPCE), but as noted in the constant volume case, these species are inherently unstable at higher temperatures. On the other hand, the formation of $\mathrm{QOOH}$ radicals via $\mathrm{RO} 2$ isomerization $\left(\mathrm{R}_{4 f}\right)$ and subsequent exothermic second $\mathrm{O}_{2}$ addition to QOOH reaction $\left(\mathrm{R}_{6 f}\right)$ drive the ignition process at later times.

- The negative contributions (opposing the explosive character of $\tau_{e, f}$ ) of reactions $\mathrm{R}_{10 f}$, $\mathrm{R}_{9 f}$ and $\mathrm{R}_{8 f}$ decrease with time while those of reactions $\mathrm{R}_{4 b}$ and $\mathrm{R}_{5 f}$ gradually increase.

- Although the net effect of reaction $\mathrm{R}_{4}$ to $\tau_{e, f}$ seems insignificant, the role of this reaction can not be dismissed, since its forward direction promotes the explosive character of $\tau_{e, f}$ by leading to the formation of the $\mathrm{QOOH}$ radical and its backward direction opposes the explosive character of $\tau_{e, f}$ by leading to the formation of the stable $\mathrm{RO}_{2}$.

The lower part of Table 4 summarizes the CSP diagnostics for the extended C6 mechanism. At point $\mathrm{P}_{1}$, the most significant contributor to the generation of $\tau_{e, f}$ is reaction $\mathrm{R}_{16 f}$, as in the $\mathrm{C} 6$ mechanism case, although its contribution is now reduced. Reaction $\mathrm{R}_{4 f}$ has a more pronounced role in promoting the explosiveness of the mixture, relative to the C6 mechanism case. Although the backward direction of $\mathrm{R}_{4}$ (i.e., $\mathrm{R}_{4 b}$ ) cancels the largest positive effect of $\mathrm{R}_{4 f}$, the net result favors the explosive character of $\tau_{e, f}$, in contrast to what was found in the $\mathrm{C} 6$ mechanism case. Reaction groups $\mathrm{R}_{18 f}$ and $\mathrm{R}_{12 f}$, which are included 
Table 4: Values of the largest $J_{k}^{e}$ (TPI) during the 1st stage ignition of the HCCI of the two n-hexane mechanisms; C6 (up) and extended C6 (down). At each point, the values of the time scale $\tau_{e, f}$ and amplitude $f^{e, f}$ of the explosive mode are displayed. Reaction groups in bold are those that are included only in the extended C6 mechanism. Refer to Fig. 5 for the selected points $\mathrm{P}_{1}, \mathrm{P}_{2}$ and $\mathrm{P}_{3}$.

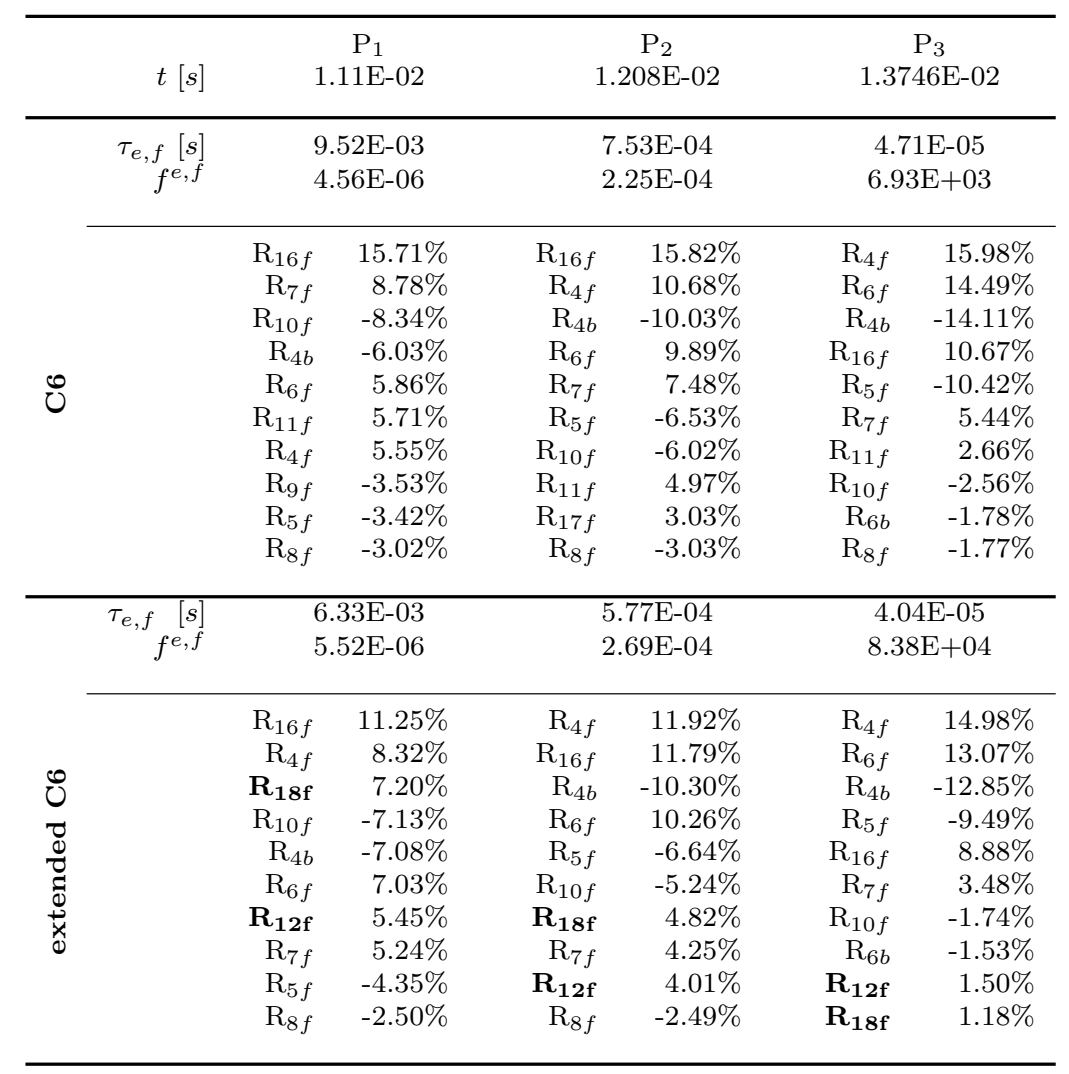

only in the extended C6 mechanism, contribute significantly to $\tau_{e, f}$, both favoring its explosive character. Additional important positive contributions to $\tau_{e, f}$ are provided by reactions $\mathrm{R}_{6 f}$ and $\mathrm{R}_{7 f}$, the former having increased and the latter decreased effect when compared to the $\mathrm{C} 6$ mechanism. The most significant opposition to $\tau_{e, f}$ (besides $\mathrm{R}_{4 b}$ ) is generated by reactions $\mathrm{R}_{10 f}, \mathrm{R}_{8 f}$ and $\mathrm{R}_{5 f}$, the first two having slightly decreased and the latter having slightly increased effect, when compared to the C6 mechanism case.

Figure 5 shows that the difference in the values of $\tau_{e, f}$ computed from the $\mathrm{C} 6$ and extended C6 mechanisms decreases with time, during the period that leads to the first stage ignition. According to Table 4, the difference is $33.51 \%$ at point $\mathrm{P}_{1}, 23.37 \%$ at point $\mathrm{P}_{2}$, $14.22 \%$ at point $\mathrm{P}_{3}$, in all points the $\mathrm{C} 6+\mathrm{O} 2$ mechanism generating a faster $\tau_{e, f}$. As seen in Table 4, this feature is mainly related to the diminishing influence of reactions $\mathrm{R}_{18 f}$ and $\mathrm{R}_{12 f}$, which are included only in the extended $\mathrm{C} 6$ mechanism. The contributions of these two reactions drop from 7.20 and $5.45 \%$ at $\mathrm{P}_{1}$ to 1.18 and $1.50 \%$ at $\mathrm{P}_{3}$. Recall that $\mathrm{R}_{12 f}$ and $\mathrm{R}_{18 f}$ are related to the formation and destruction, respectively, of KDHP species, which are important for $\mathrm{OH}$ radical production. As the first stage ignition proceeds, the temperature rise thermodynamically inhibits $\mathrm{R}_{12 f}$, hence limiting the KDHP production. This feature is accompanied by a faster rise to dominance of reaction $\mathrm{R}_{4 f}$ and a faster decline of the influence of reaction $\mathrm{R}_{16 f}$.

At $\mathrm{P}_{3}$ in Table 4, no significant differences are found in the relative contributions from different reactions to $\tau_{e, f}$, when using the C6 or the extended C6 mechanism. This suggests 
that the influence of the third sequential $\mathrm{O}_{2}$ addition reactions, which are included in the extended C6 mechanism, has decreased considerably.

In summary, the following remarks can be made for the comparison of the two mechanisms during the first stage ignition:

- Reactions $\mathrm{R}_{18 f}$ and $\mathrm{R}_{12 f}$, which are included only in the extended $\mathrm{C} 6$ mechanism, play a significant role favoring the explosive character of $\tau_{e, f}$, thus promoting ignition, although their effects diminish with time. As in the constant volume autoignition case, these reactions rely on the formation of highly oxidized intermediates which are inherently unstable at higher temperatures, so as the temperature increases during the first stage ignition process, these reactions become less important.

- The effect of reactions $\mathrm{R}_{16 f}$ and $\mathrm{R}_{7 f}$, which both promote the explosiveness of the mixture, diminishes in the extended C6 mechanism. The same applies for reactions $\mathrm{R}_{10 f}$ and $\mathrm{R}_{8 f}$ (a set of ten reactions with average contribution $-0.25 \%$ each), both of which favor the dissipative nature of $\tau_{e, f}$ retarding ignition.

- The effect of reactions $\mathrm{R}_{6 f}$ and $\mathrm{R}_{5 f}$ is increased in the extended C6 mechanism, with the former favoring and the second opposing the explosive character of $\tau_{e, f}$.

- The net effect of reaction $\mathrm{R}_{4}$ is always positive when using the extended C6 mechanism, thus promoting ignition, and is much stronger when compared to the net effect in the case where the C6 mechanism is used; in the latter case the net effect is negative at the start of the process and then gradually becomes positive.

- The smaller timescale and the larger amplitude values in the case of the extended C6 mechanism indicate that the explosive mode drives the process faster and its impact is stronger, when compared to the C6 mechanism.

\subsubsection{Second-stage ignition}

To identify the dominant chemical reactions during the second stage ignition, the TPI was computed at four representative points in that period. The selected four points are shown in Fig. 6; points $\mathrm{P}_{6}$ and $\mathrm{P}_{7}$ refer to the points in time where $\tau_{e, f}$ reaches a local and a global minimum value, respectively. 
Table 5: The reactions providing significant contribution to the generation of the fast time scale $\tau_{e, f}$, during the 2 nd stage ignition in HCCI of the two hexane mechanisms [2, 35].

$$
\begin{aligned}
1: & \mathrm{H}+\mathrm{O}_{2} \leftrightarrow \mathrm{O}+\mathrm{OH} \\
4: & \mathrm{O}+\mathrm{H}_{2} \mathrm{O} \leftrightarrow 2 \mathrm{OH} \\
9: & \mathrm{H}+\mathrm{O}_{2}(+\mathrm{M}) \leftrightarrow \mathrm{HO}_{2}(+\mathrm{M}) \\
13 / 14: & \mathrm{OH}+\mathrm{HO}_{2} \leftrightarrow \mathrm{H} 2 \mathrm{O}+\mathrm{O}_{2}
\end{aligned}
$$

$$
\begin{aligned}
15 / 16: & 2 \mathrm{HO}_{2} \leftrightarrow \mathrm{H}_{2} \mathrm{O}_{2}+\mathrm{O}_{2} \\
17: & \mathrm{H}_{2} \mathrm{O}_{2}(+\mathrm{M}) \leftrightarrow 2 \mathrm{OH}(+\mathrm{M}) \\
21 / 22: & \mathrm{H}_{2} \mathrm{O}_{2}+\mathrm{OH} \leftrightarrow \mathrm{H}_{2} \mathrm{O}+\mathrm{HO}_{2} \\
25 / 26: & \mathrm{CO}+\mathrm{OH} \leftrightarrow \mathrm{CO}_{2}+\mathrm{H} \\
301: & \mathrm{C}_{2} \mathrm{H}_{4}+\mathrm{OH} \leftrightarrow \mathrm{C}_{2} \mathrm{H}_{3}+\mathrm{H}_{2} \mathrm{O}
\end{aligned}
$$
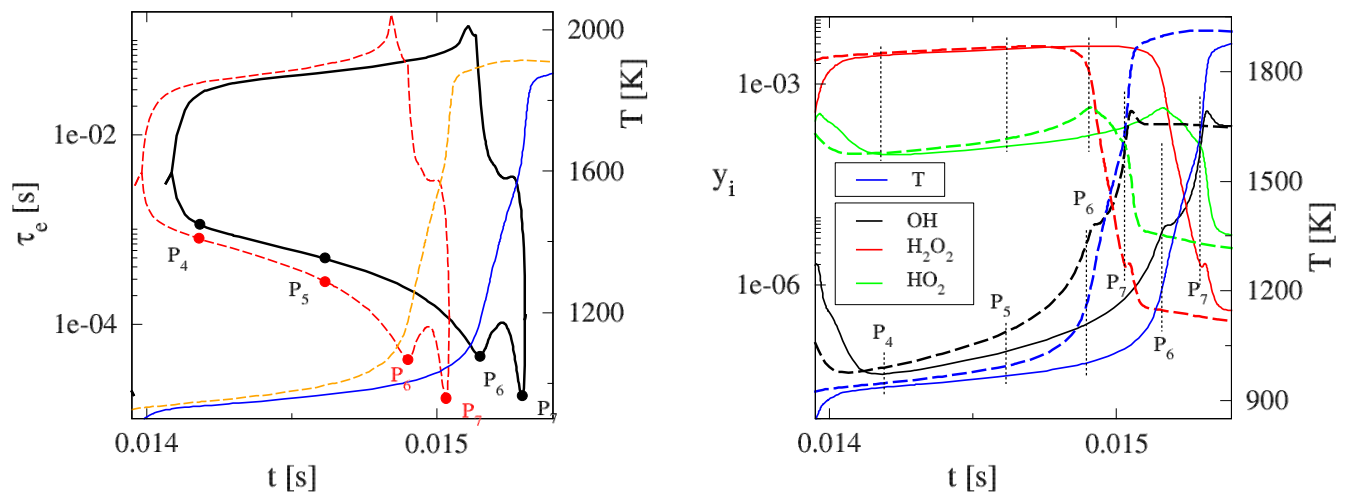

Figure 6: Left: The evolution of the explosive timescales and temperature during the 2nd stage ignition. $\mathrm{P}_{4}-\mathrm{P}_{7}$ represent the points that CSP diagnostics were generated for the $\tau_{e, f}$. Right: The evolution of the species mass fractions of $\mathrm{OH}, \mathrm{H}_{2} \mathrm{O}_{2}, \mathrm{HO}_{2}$ and of the temperature during the 2nd stage ignition. Both left and right: C6 (solid lines) and extended C6 (dashed lines); $\mathrm{p}(0)=1 \mathrm{~atm}$, $\phi=0.4$ and $\mathrm{T}(0)=336 \mathrm{~K}$.

The reactions exhibiting the largest TPI values for both mechanisms during the second stage ignition are listed in Table 5. The reaction pairs 13/14, 15/16, 21/22 and 25/26 are duplicate ones, with different rate constants, accounting for the high and low temperature regime, respectively. As the listed reactions indicate, this stage is dominated by hydrogen related chemistry, essentially different than the dominant chemistry during the first stage ignition. The only carbon related ones are the $\mathrm{CO}$ to $\mathrm{CO}_{2}$ reactions $25 / 26(\mathrm{CO}+\mathrm{OH} \rightarrow$ $\left.\mathrm{CO}_{2}+\mathrm{H}\right)$ and the $\mathrm{C}_{2} \mathrm{H}_{4}$-oxidation reaction $301 \mathrm{f}\left(\mathrm{C}_{2} \mathrm{H}_{4}+\mathrm{OH} \rightarrow \mathrm{C}_{2} \mathrm{H}_{3}+\mathrm{H}_{2} \mathrm{O}\right)$.

Table 6 lists the reactions with the largest TPI values at the four selected points $\mathrm{P}_{4}-\mathrm{P}_{7}$, shown in Fig. 6, for both C6 and extended C6 kinetics mechanisms. It is shown that in both cases during the second ignition delay $\tau_{e, f}$ is generated by the same set of reactions.

Specifically, at points $\mathrm{P}_{4}$ and $\mathrm{P}_{5}$, which represent the beginning of the second stage ignition process, Table 6 shows that the dominant contributor to $\tau_{e, f}$ is the chain branching reaction $17 \mathrm{f}\left(\mathrm{H}_{2} \mathrm{O}_{2}(+\mathrm{M}) \rightarrow 2 \mathrm{OH}(+\mathrm{M})\right)$, favoring its explosive character. The key role of this reaction in promoting the ignition has been identified in the oxidation of a variety of fuels, like $\mathrm{CH}_{4}, \mathrm{DME}$ and EtOH $[39,61,73]$. However, reaction $17 f$ was shown to exhibit negligible influence on $\tau_{e, f}$ in the case of $\mathrm{H}_{2}$ oxidation [38]. Table 6 also shows that the major opposition to the generation of $\tau_{e, f}$ at $\mathrm{P}_{4}$ and $\mathrm{P}_{5}$ is produced by the chain termination reactions $15 / 16 \mathrm{f}\left(2 \mathrm{HO}_{2} \rightarrow \mathrm{H}_{2} \mathrm{O}_{2}+\mathrm{O}_{2}\right)$, which consume the $\mathrm{HO}_{2}$ radical and form two stable molecules. Similar behavior was observed in the case of $\mathrm{CH}_{4}, \mathrm{DME}$ and EtOH oxidation $[61,73]$. Table 6 shows that additional negative contribution at $\mathrm{P}_{4}$ and $\mathrm{P}_{5}$, opposing the explosive character of $\tau_{e, f}$, is provided by the chain termination reactions $21 / 22 \mathrm{f}\left(\mathrm{H}_{2} \mathrm{O}_{2}+\mathrm{OH}\right.$ $\rightarrow \mathrm{H}_{2} \mathrm{O}+\mathrm{HO}_{2}$ ), which consume $\mathrm{H}_{2} \mathrm{O}_{2}$ and $\mathrm{OH}$ radicals and form $\mathrm{H}_{2} \mathrm{O}$ and $\mathrm{HO}_{2}$. Reactions 
Table 6: Values of the largest Time scale Participation Indices $J_{k}^{e}$ (TPI) during the 2nd stage ignition of the HCCI of the two n-hexane mechanisms; C6 (up) and extended C6 (down). Refer to Fig. 6 for the selected numbered points. Points $\mathrm{P}_{4}$ and $\mathrm{P}_{5}$ refer to the same time in both mechanisms, while $\mathrm{P}_{6}$ and $\mathrm{P}_{7}$ refer to the points in time where $\tau_{e, f}$ reaches a local and a global minimum value, respectively.

\begin{tabular}{|c|c|c|c|c|c|c|c|c|}
\hline $\mathbf{t}[s]$ & \multicolumn{2}{|c|}{$\begin{array}{c}\mathrm{P}_{4} \\
1.4180 \mathrm{E}-02\end{array}$} & \multicolumn{2}{|c|}{$\begin{array}{c}\mathrm{P}_{5} \\
1.4616 \mathrm{E}-02 \\
\end{array}$} & \multicolumn{2}{|c|}{$\begin{array}{c}\mathrm{P}_{6} \\
1.5149 \mathrm{E}-02 / 1.4900 \mathrm{E}-02 \\
\end{array}$} & \multicolumn{2}{|c|}{$\begin{array}{c}\mathrm{P}_{7} \\
\text { 1.529E-02/1.503E-02 }\end{array}$} \\
\hline $\begin{array}{r}\tau_{e, f}[s] \\
f_{e, f} \\
\end{array}$ & \multicolumn{2}{|c|}{$\begin{array}{r}1.13 \mathrm{E}-03 \\
6.42 \mathrm{E}+04 \\
\end{array}$} & \multicolumn{2}{|c|}{$\begin{array}{c}5.22 \mathrm{E}-04 \\
1.16 \mathrm{E}+05 \\
\end{array}$} & \multicolumn{2}{|c|}{$\begin{array}{r}4.59 \mathrm{E}-05 \\
2.91 \mathrm{E}+06 \\
\end{array}$} & \multicolumn{2}{|c|}{$\begin{array}{r}1.75 \mathrm{E}-05 \\
6.18 \mathrm{E}+06 \\
\end{array}$} \\
\hline Uి & $\begin{array}{r}17 \mathrm{f} \\
15 / 16 \mathrm{f} \\
21 / 22 \mathrm{f}\end{array}$ & $\begin{array}{l}23.47 \% \\
-5.72 \% \\
-3.41 \%\end{array}$ & $\begin{array}{r}17 \mathrm{f} \\
15 / 16 \mathrm{f} \\
21 / 22 \mathrm{f}\end{array}$ & $\begin{array}{l}25.98 \% \\
-5.65 \% \\
-4.29 \%\end{array}$ & $\begin{array}{r}17 \mathrm{f} \\
13 / 14 \mathrm{f} \\
301 \mathrm{f} \\
1 \mathrm{f}\end{array}$ & $\begin{array}{r}15.20 \% \\
-9.06 \% \\
7.65 \% \\
6.56 \%\end{array}$ & $\begin{array}{r}1 \mathrm{f} \\
9 \mathrm{f} \\
25 / 26 \mathrm{f} \\
13 / 14 \mathrm{f} \\
1 \mathrm{~b} \\
4 \mathrm{f}\end{array}$ & $\begin{array}{r}32.51 \% \\
-22.07 \% \\
12.81 \% \\
-8.18 \% \\
-7.72 \% \\
7.11 \%\end{array}$ \\
\hline $\begin{array}{r}\tau_{e, f}[s] \\
f_{e, f} \\
\end{array}$ & \multicolumn{2}{|c|}{$\begin{array}{r}8.05 \mathrm{E}-04 \\
7.82 \mathrm{E}+04 \\
\end{array}$} & \multicolumn{2}{|c|}{$\begin{array}{r}2.82 \mathrm{E}-04 \\
2.21 \mathrm{E}+05 \\
\end{array}$} & \multicolumn{2}{|c|}{$\begin{array}{r}4.24 \mathrm{E}-05 \\
3.14 \mathrm{E}+06 \\
\end{array}$} & \multicolumn{2}{|c|}{$\begin{array}{r}1.67 \mathrm{E}-05 \\
6.53 \mathrm{E}+06 \\
\end{array}$} \\
\hline $\begin{array}{l}0 \\
0 \\
0 \\
0 \\
0 \\
0 \\
0 \\
\dot{x} \\
0\end{array}$ & $\begin{array}{r}17 \mathrm{f} \\
15 / 16 \mathrm{f} \\
21 / 22 \mathrm{f}\end{array}$ & $\begin{array}{l}24.26 \% \\
-6.01 \% \\
-3.61 \%\end{array}$ & $\begin{array}{r}17 \mathrm{f} \\
15 / 16 \mathrm{f} \\
21 / 22 \mathrm{f}\end{array}$ & $\begin{array}{l}27.68 \% \\
-5.13 \% \\
-5.10 \%\end{array}$ & $\begin{array}{r}17 \mathrm{f} \\
13 / 14 \mathrm{f} \\
301 \mathrm{f} \\
1 \mathrm{f}\end{array}$ & $\begin{array}{r}15.50 \% \\
-8.87 \% \\
7.55 \% \\
6.29 \%\end{array}$ & $\begin{array}{r}1 \mathrm{f} \\
9 \mathrm{f} \\
25 / 26 \mathrm{f} \\
13 / 14 \mathrm{f} \\
1 \mathrm{~b} \\
4 \mathrm{f}\end{array}$ & $\begin{array}{r}32.47 \% \\
-22.02 \% \\
12.88 \% \\
-8.46 \% \\
-7.47 \% \\
7.03 \%\end{array}$ \\
\hline
\end{tabular}

21/22f exhibited a similar behavior during the initiation of the autoignition of a $\mathrm{H}_{2} \mathrm{O}_{2}$ enriched $\mathrm{CH}_{4}$ /air mixture [73], but exhibited negligible contribution to $\tau_{e, f}$ in the case a pure $\mathrm{CH}_{4}$ /air mixture [38, 52].

Table 6 shows that the dominance of reaction $17 \mathrm{f}$ extends to point $\mathrm{P}_{6}$, although its contribution is decreased. Its action is now complemented by that of the $\mathrm{C}_{2} \mathrm{H}_{4}$-oxidation reaction $301 \mathrm{f}\left(\mathrm{C}_{2} \mathrm{H}_{4}+\mathrm{OH} \rightarrow \mathrm{C}_{2} \mathrm{H}_{3}+\mathrm{H}_{2} \mathrm{O}\right)$ and the chain reaction $1 \mathrm{f}\left(\mathrm{H}+\mathrm{O}_{2} \rightarrow \mathrm{O}\right.$ $+\mathrm{OH})$. The role of the latter reaction at this explosive stage is well known and widely documented [38, 61, 68, 73]. However, such an influence of reaction 301f is not reported in the existing literature, so it is further investigated in a section that follows. Note that at point $\mathrm{P}_{6}$ the reaction opposing the most the explosive character of $\tau_{e, f}$ is the $\mathrm{OH}$-consuming termination reaction $13 / 14 \mathrm{f}\left(\mathrm{OH}+\mathrm{HO}_{2} \rightarrow \mathrm{H}_{2} \mathrm{O}+\mathrm{O}_{2}\right)$ and that $\mathrm{OH}$ is reactant in reaction $301 f$.

At point $\mathrm{P}_{7}$, where $\tau_{e, f}$ obtains its minimum value and the temperature undergoes a step rise, Table 6 shows that chain branching reaction $1 \mathrm{f}$ dominates the explosive dynamics, assisted by the strongly exothermic reaction 25/26f $\left(\mathrm{CO}+\mathrm{OH} \leftrightarrow \mathrm{CO}_{2}+\mathrm{H}\right)$. This influence of reactions $1 \mathrm{f}$ and $25 / 26 \mathrm{f}$ was shown to manifest in a number of hydrocarbon fuels at the final part of the explosive stage; e.g., [39, 61, 70, 72, 73]. The major opposition to the explosive character of $\tau_{e, f}$ at $\mathrm{P}_{7}$ originates from the termination reaction $9 \mathrm{f}\left(\mathrm{H}+\mathrm{O}_{2}(+\mathrm{M}) \rightarrow \mathrm{HO}_{2}\right.$ $(+\mathrm{M}))$, supported by reactions $13 / 14 \mathrm{f}$ and $1 \mathrm{~b}$.

In conclusion, the following remarks can be made regarding the behavior of the $\mathrm{C} 6$ and extended C6 mechanisms during the second stage ignition:

- None of the third sequential $\mathrm{O}_{2}$ addition reactions that are included only in the extended C6 mechanism, seem to be significant for the explosivity of the mixture, in contrast with the first stage ignition where reaction groups $\mathrm{R}_{18 f}$ and $\mathrm{R}_{12 f}$ played key roles.

- The explosive characteristics of the mixture are influenced by reactions that are in- 
cluded in both the C6 and extended C6 mechanisms. The influence of each reaction in that set is the same, both qualitatively and quantitively.

\subsubsection{Validation of the results}

To validate the findings reported previously in the context of a variable volume HCCI engine, regarding the elementary reactions contributing the most to the explosive timescale $\tau_{e, f}$, and as a result to the ignition delay time, a standard sensitivity analysis was performed by perturbing the rate constant of selected reaction groups. In particular, the reaction rate constants of selected reactions or reaction groups were increased by $50 \%$. The differences in the temperature profiles, relative to the unperturbed case, were indicative of the sensitivity of the mechanism to the selected reaction group. The results are displayed in Fig. 7 for both C6 and extended C6 mechanisms under consideration.
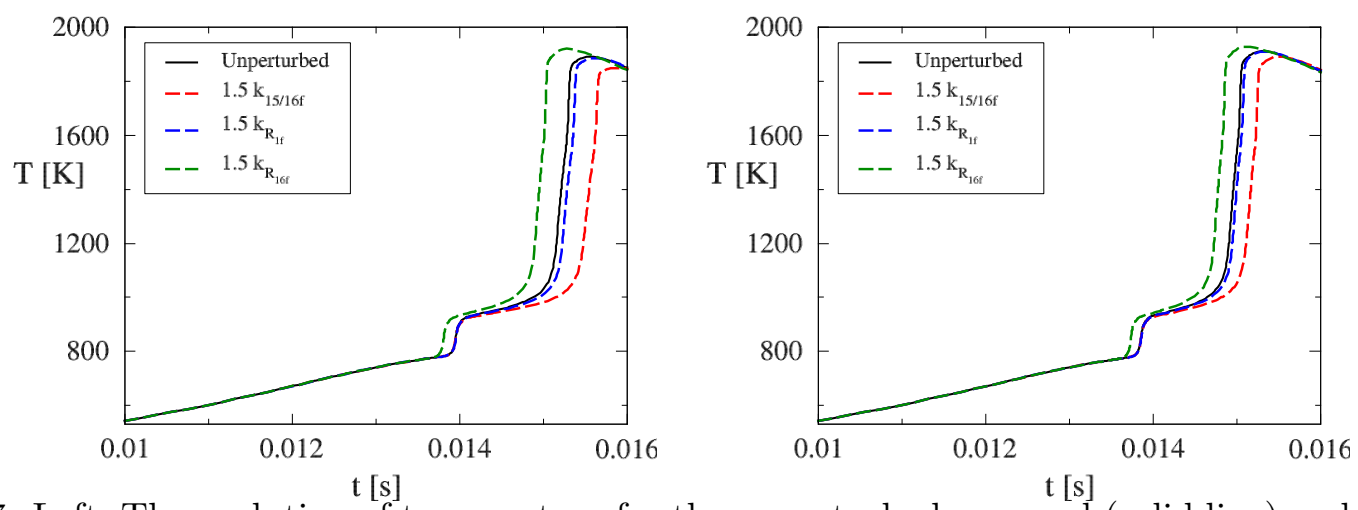

Figure 7: Left: The evolution of temperature for the unperturbed case and (solid line) and the four perturbed cases; C6 (left) and extended C6 (right); $\mathrm{p}(0)=1 \mathrm{~atm}, \phi=0.4$ and $\mathrm{T}(0)=336 \mathrm{~K}$.

The reaction 15/16f (see Table 5) was found to provide major opposition to the generation of $\tau_{e, f}$, in both mechanisms, during the second stage ignition (see Table 6), while its influence in the first stage ignition was negligible (see Table 4). Accordingly, as shown in Fig. 7, the perturbation of the rate constant of this reaction notably retards the temperature increase during the second stage ignition, leaving the first stage unaltered. Reaction 16f (see Table 2) was found to have significant positive contribution to the generation of $\tau_{e, f}$ during the first stage ignition, favoring its explosive character, in both mechanisms. The results of Fig. 7 confirm the significant role of this reaction group in promoting the first stage ignition. Finally, reaction $1 \mathrm{f}$ was found to have small contribution to the generation of $\tau_{e, f}$ during both stages in both mechanisms. In fact, it exhibited negligible contribution up to the first ignition stage and very small positive contribution up to the second stage. These predictions are fully reproduced in the unperturbed and perturbed profiles shown in Fig. 7.

\section{The influence of $\mathrm{C}_{2} \mathrm{H}_{4}$}

The $\mathrm{C}_{2} \mathrm{H}_{4}$-oxidation reaction $301 \mathrm{f}\left(\mathrm{C}_{2} \mathrm{H}_{4}+\mathrm{OH} \rightarrow \mathrm{C}_{2} \mathrm{H}_{3}+\mathrm{H}_{2} \mathrm{O}\right)$, which was shown to contribute to $\tau_{e, f}$ during the second stage of the autoignition in a variable volume HCCI engine, represents a break-up venue of ethylene, a fuel by itself which has been studied extensively $[79,80]$. It was found that the evolution of the mass fraction of ethylene relates directly to the acceleration of $\tau_{e, f}$ that is manifested in the final stages of the homogeneous 


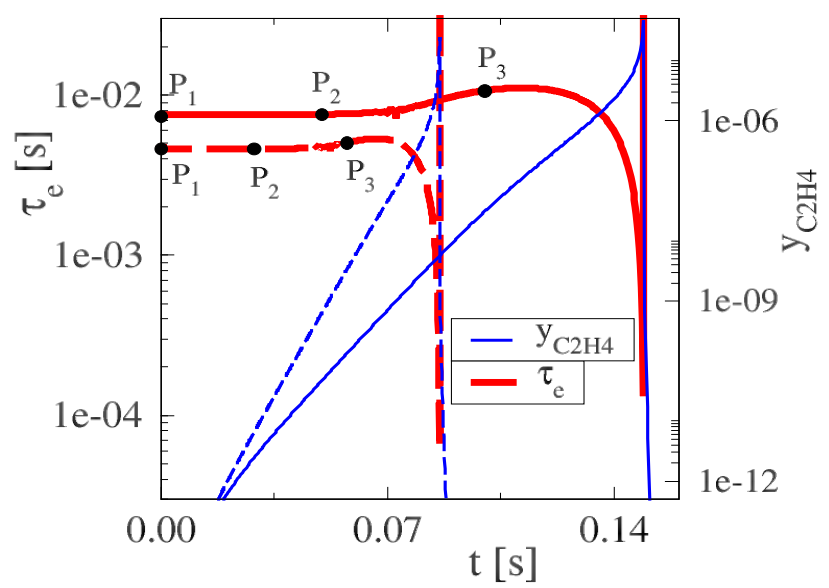

Figure 8: The evolution of the explosive timescales and the mass fraction of $\mathrm{C}_{2} \mathrm{H}_{4}$ during homogeneous autoignition at constant volume. C6 (solid lines) and extended C6 (dashed lines); $\mathrm{p}(0)=60$ atm, $\phi=1$ and $\mathrm{T}(0)=600 \mathrm{~K}$.

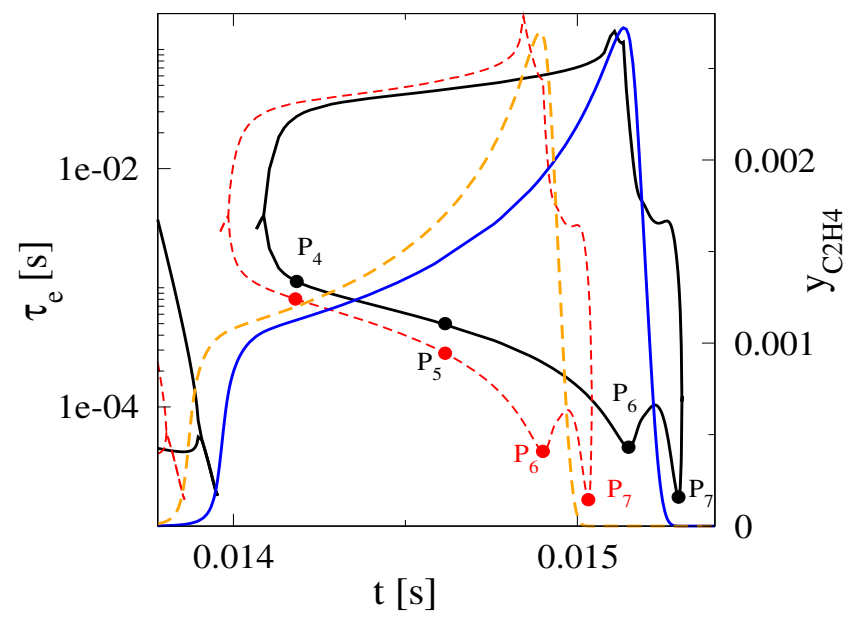

Figure 9: The evolution of the explosive timescales and the mass fraction of $\mathrm{C}_{2} \mathrm{H}_{4}$ during the 2nd stage ignition. C6 (solid lines) and extended C6 (dashed lines); $\mathrm{p}(0)=1 \mathrm{~atm}, \phi=0.4$ and $\mathrm{T}(0)=336$ $\mathrm{K}$.

autoignition at constant volume (see Section 4.1) and of the autoignition in a variable volume HCCI engine (see Section 4.2.2). This relation is manifested in Figs. 8 and 9 where the profile of the $\mathrm{C}_{2} \mathrm{H}_{4}$ mass fraction is compared to that of $\tau_{e, f}$.

For the homogeneous autoignition case, Fig. 8 shows that the mass fraction of $\mathrm{C}_{2} \mathrm{H}_{4}$ increases linearly up to the last part of the explosive stage, where it rises at a much faster rate and then at the end of this stage decreases at an even faster rate.

In contrast, For the HCCI engine case Fig. 9 shows that $\mathrm{C}_{2} \mathrm{H}_{4}$ is rapidly produced immediately after the development of the first stage ignition and continues to increase until about point $\mathrm{P}_{6}$ where the local minimum of $\tau_{e, f}$ is reached. Until that point, the increasing mass fraction of $\mathrm{C}_{2} \mathrm{H}_{4}$ is associated with an accelerating $\tau_{e, f}$. From that point on, its mass fraction decreases rapidly and $\tau_{e, f}$ tends to decelerate. Figure 9 thus suggests that the development of $\tau_{e, f}$ and its acceleration during the period that leads to the second stage ignition is related to the increased levels of ethylene. 


\section{Conclusions}

The chemical kinetics driving the ignition dynamics of n-hexane/air mixtures were investigated in both constant volume and HCCI engine conditions. The analysis was conducted at a wide range of initial conditions, using algorithmic tools from CSP, in the context of two chemical kinetic mechanisms, with and without third sequential $\mathrm{O}_{2}$ addition reactions [2, 35]. The results numerically proved that the third sequential $\mathrm{O}_{2}$ addition reaction pathways play a significant role in the evolution of the ignition process; its effect being more pronounced in the constant volume autoignition cases.

An investigation of the ignition delay time under constant volume conditions revealed that the third sequential $\mathrm{O}_{2}$ addition reaction pathways are favored at lower temperatures, higher pressures and lean equivalence ratios. In the constant volume case, reactions of KDHP $\rightarrow$ products $+\mathrm{OH}$ contribute significantly to the dynamics of the system, favoring the explosiveness of the mixture. On the other hand, reactions of $\mathrm{T}(\mathrm{OOH})_{3} \leftrightarrow \mathrm{ODHP}+\mathrm{HO}_{2}$ and $\mathrm{T}(\mathrm{OOH})_{3} \leftrightarrow \mathrm{DHPCE}+\mathrm{OH}$ (also included exclusively in the extended mechanism) provide negligible contributions, with the former opposing and the latter favoring the explosiveness of the mixture.

Under HCCI conditions, the first stage ignition dynamics is characterized primarily by reactions of $\mathrm{KHP} \rightarrow \mathrm{OQ}^{\prime}=\mathrm{O}+\mathrm{OH}$ and $\mathrm{QOOH}+\mathrm{O}_{2} \rightarrow \mathrm{O}_{2} \mathrm{QOOH}$. Both reaction groups accelerate the ignition process, while the effect of the former (latter) is larger for the (extended) $\mathrm{C} 6$ mechanism. The third sequential $\mathrm{O}_{2}$ addition reactions of KDHP $\rightarrow$ products $+\mathrm{OH}$ and $\mathrm{P}(\mathrm{OOH})_{2}+\mathrm{O}_{2} \rightarrow \mathrm{OOP}(\mathrm{OOH})_{2}$ contribute significantly to the process, although their role decays with time and becomes trivial at the end of the first stage. The major opposition to the evolution of the process is produced by reactions $\mathrm{RO}_{2} \rightarrow$ olefin $+\mathrm{HO}_{2}$, while the positive net effect of reactions $\mathrm{RO}_{2} \leftrightarrow$ QOOH becomes larger when the extended C6 kinetics mechanism is used. The analysis also showed that during the second ignition stage, none of the third sequential $\mathrm{O}_{2}$ addition reactions that are included only in the extended C6 mechanism, are significant for the evolution of the process. The process during the second ignition stage is dominated almost exclusively by hydrogen-related chemistry, with the same set of reactions highlighted for both mechanisms.

It is noted that the sets of reactions identified being important in both cases of the current study, differ, in general, from the set identified in the work of Zhang et al., where the sensitivity analysis at $\mathrm{T}(0)=800 \mathrm{~K}, \mathrm{p}(0)=15 \mathrm{~atm}, \phi=1$ identified $\mathrm{QOOH}+\mathrm{O}_{2} \rightarrow \mathrm{O}_{2} \mathrm{QOOH}$ and $\mathrm{H}_{2} \mathrm{O}_{2}(+\mathrm{M}) \rightarrow 2 \mathrm{OH}(+\mathrm{M})$ as the most important reactions of the system.

This study effectively demonstrated the utility and advantage of CSP tools for understanding ignition dynamics in systems with complex reaction networks. Important similarities and differences between the ignition dynamics under constant volume cases and HCCI engine conditions were revealed. This study also highlights the fact that the framework for the oxidation of hydrocarbons, which so far included two sequential $\mathrm{O}_{2}$ addition reactions, has to be revised in order to account for further $\mathrm{O}_{2}$ addition reactions, as proposed by Wang et al.[1, 34]. Although the current analysis was conducted on the basis of n-hexane, it is believed that the third sequential of $\mathrm{O}_{2}$ addition pathways apply to hydrocarbons with six or more carbon atoms. Numerical investigations using different n-alkanes or hydrocarbons with other functional groups would provide further detailed insights about the role of the third sequential $\mathrm{O}_{2}$ addition pathways. 


\section{Acknowledgments}

This work was sponsored by competitive research funding from King Abdullah University of Science and Technology.

\section{References}

[1] Z. Wang, S. Y. Mohamed, L. Zhang, K. Moshammer, D. M. Popolan-Vaida, V. S. B. Shankar, A. Lucassen, L. Ruwe, N. Hansen, P. Dagaut, S. M. Sarathy, New insights into the low-temperature oxidation of 2-methylhexane, Proc. Combust. Inst. 36 (1) (2017) $373-382$.

[2] K. Zhang, C. Banyon, C. Togbé, P. Dagaut, J. Bugler, H. J. Curran, An experimental and kinetic modeling study of n-hexane oxidation, Combust. Flame 162 (11) (2015) 4194-4207.

[3] M. Yao, Z. Zheng, H. Liu, Progress and recent trends in homogeneous charge compression ignition (HCCI) engines, Prog. Energ. Combust. 35 (5) (2009) 398-437.

[4] C. Noehre, M. Andersson, B. Johansson, A. Hultqvist, Characterization of partially premixed combustion, Tech. rep., SAE Tech. Pap. (2006).

[5] M. Lewander, K. Ekholm, B. Johansson, P. Tunestål, N. Milovanovic, N. Keeler, T. Harcombe, P. Bergstrand, Investigation of the combustion characteristics with focus on partially premixed combustion in a heavy duty engine, SAE International Journal of Fuels and Lubricants 1 (2008-01-1658) (2008) 1063-1074.

[6] M. Lewander, B. Johansson, P. Tunestål, N. Keeler, S. Tullis, N. Milovanovic, P. Bergstrand, Evaluation of the operating range of partially premixed combustion in a multi cylinder heavy duty engine with extensive EGR, Tech. rep., SAE Tech. Pap. (2009).

[7] V. Manente, B. Johansson, P. Tunestal, Partially premixed combustion at high load using gasoline and ethanol, a comparison with diesel, Tech. rep. (2009).

[8] X.-C. Lü, W. Chen, Z. Huang, A fundamental study on the control of the HCCI combustion and emissions by fuel design concept combined with controllable EGR. Part 1. The basic characteristics of HCCI combustion, Fuel 84 (9) (2005) 1074-1083.

[9] X.-C. Lü, W. Chen, Z. Huang, A fundamental study on the control of the HCCI combustion and emissions by fuel design concept combined with controllable EGR. Part 2. Effect of operating conditions and EGR on HCCI combustion, Fuel 84 (9) (2005) 1084-1092.

[10] S. Saxena, I. D. Bedoya, Fundamental phenomena affecting low temperature combustion and HCCI engines, high load limits and strategies for extending these limits, Prog. Energ. Combust. 39 (5) (2013) 457-488. 
[11] R. Compton, G. Hancock, M. Pilling, Comprehensive chemical kinetics: Lowtemperature combustion and autoignition (1997).

[12] C. K. Westbrook, F. L. Dryer, Chemical kinetic modeling of hydrocarbon combustion, Prog. Energ. Combust. 10 (1) (1984) 1-57.

[13] W. J. Pitz, C. J. Mueller, Recent progress in the development of diesel surrogate fuels, Prog. Energ. Combust. 37 (3) (2011) 330-350.

[14] F. Battin-Leclerc, Detailed chemical kinetic models for the low-temperature combustion of hydrocarbons with application to gasoline and diesel fuel surrogates, Prog. Energ. Combust. 34 (4) (2008) 440-498.

[15] J. Cartlidge, C. Tipper, The peroxides formed during hydrocarbon slow combustion and their role in the mechanism, in: P. Roy. Soc. Lond. A Mat., Vol. 261, 1961, pp. 388-401.

[16] R. Cox, J. Cole, Chemical aspects of the autoignition of hydrocarbon-air mixtures, Combust. Flame 60 (2) (1985) 109-123.

[17] H. J. Curran, P. Gaffuri, W. J. Pitz, C. K. Westbrook, A comprehensive modeling study of n-heptane oxidation, Combust. Flame 114 (1) (1998) 149-177.

[18] H. J. Curran, P. Gaffuri, W. Pitz, C. Westbrook, A comprehensive modeling study of iso-octane oxidation, Combust. Flame 129 (3) (2002) 253-280.

[19] S. M. Sarathy, C. K. Westbrook, M. Mehl, W. J. Pitz, C. Togbe, P. Dagaut, H. Wang, M. A. Oehlschlaeger, U. Niemann, K. Seshadri, F. Egolfopoulos, T. Lu, Comprehensive chemical kinetic modeling of the oxidation of 2-methylalkanes from $\mathrm{C}_{7}$ to $\mathrm{C}_{20}$, Combust. Flame 158 (12) (2011) 2338-2357.

[20] C. K. Westbrook, W. J. Pitz, O. Herbinet, H. J. Curran, E. J. Silke, A comprehensive detailed chemical kinetic reaction mechanism for combustion of n-alkane hydrocarbons from n-octane to n-hexadecane, Combust. Flame 156 (1) (2009) 181-199.

[21] S. M. Sarathy, T. Javed, F. Karsenty, A. Heufer, W. Wang, S. Park, A. Elwardany, A. Farooq, C. K. Westbrook, W. J. Pitz, M. A. Oehlschlaeger, G. Dayma, H. J. Curran, P. Dagaut, A comprehensive combustion chemistry study of 2, 5-dimethylhexane, Combust. Flame 161 (6) (2014) 1444-1459.

[22] K. Zhang, C. Banyon, J. Bugler, H. J. Curran, A. Rodriguez, O. Herbinet, F. BattinLeclerc, C. B'Chir, K. A. Heufer, An updated experimental and kinetic modeling study of n-heptane oxidation, Combust. Flame 172 (2016) 116-135.

[23] J. Bugler, K. P. Somers, E. J. Silke, H. J. Curran, Revisiting the kinetics and thermodynamics of the low-temperature oxidation pathways of alkanes: A case study of the three pentane isomers, J. Phys. Chem. A 119 (28) (2015) 7510-7527.

[24] F. Battin-Leclerc, E. Blurock, R. Bounaceur, R. Fournet, P.-A. Glaude, O. Herbinet, B. Sirjean, V. Warth, Towards cleaner combustion engines through groundbreaking detailed chemical kinetic models, Chem. Soc. Rev. 40 (9) (2011) 4762-4782. 
[25] C. W. Gao, J. W. Allen, W. H. Green, R. H. West, Reaction mechanism generator: Automatic construction of chemical kinetic mechanisms, Comput. Phys. Commun. 203 (2016) 212-225.

[26] E. Ranzi, T. Faravelli, P. Gaffuri, A. Sogaro, Low-temperature combustion: Automatic generation of primary oxidation reactions and lumping procedures, Combust. Flame 102 (1) (1995) 179-192.

[27] E. Ranzi, P. Gaffuri, T. Faravelli, P. Dagaut, A wide-range modeling study of n-heptane oxidation, Combust. Flame 103 (1) (1995) 91-106.

[28] E. Ranzi, A. Frassoldati, S. Granata, T. Faravelli, Wide-range kinetic modeling study of the pyrolysis, partial oxidation, and combustion of heavy n-alkanes, Ind. Eng. Chem. Res. 44 (14) (2005) 5170-5183.

[29] M. Pelucchi, M. Bissoli, C. Cavallotti, A. Cuoci, T. Faravelli, A. Frassoldati, E. Ranzi, A. Stagni, Improved kinetic model of the low-temperature oxidation of n-heptane, Energ. Fuel 28 (11) (2014) 7178-7193.

[30] L. Cai, H. Pitsch, S. Y. Mohamed, V. Raman, J. Bugler, H. Curran, S. M. Sarathy, Optimized reaction mechanism rate rules for ignition of normal alkanes, Combust. Flame 173 (2016) 468-482.

[31] L. Cai, H. Pitsch, Optimized chemical mechanism for combustion of gasoline surrogate fuels, Combust. Flame 162 (5) (2015) 1623-1637.

[32] H. Wang, D. A. Sheen, Combustion kinetic model uncertainty quantification, propagation and minimization, Prog. Energ. Combust. 47 (2015) 1-31.

[33] S. Y. Mohamed, L. Cai, F. Khaled, C. Banyon, Z. Wang, M. J. Al Rashidi, H. Pitsch, H. J. Curran, A. Farooq, S. M. Sarathy, Modeling ignition of a heptane isomer: Improved thermodynamics, reaction pathways, kinetics, and rate rule optimizations for 2-methylhexane, J. Phys. Chem. A 120 (14) (2016) 2201-2217.

[34] Z. Wang, L. Zhang, K. Moshammer, D. M. Popolan-Vaida, V. S. B. Shankar, A. Lucassen, C. Hemken, C. A. Taatjes, S. R. Leone, K. Kohse-Höinghaus, N. Hansen, P. Dagaut, S. M. Sarathy, Additional chain-branching pathways in the low-temperature oxidation of branched alkanes, Combust. Flame 164 (2016) 386-396.

[35] Z. Wang, S. M. Sarathy, Third $\mathrm{O}_{2}$ addition reactions promote the low-temperature auto-ignition of n-alkanes, Combust. Flame 165 (2016) 364-372.

[36] T. Turányi, Applications of sensitivity analysis to combustion chemistry, Reliab. Eng. Syst. Safe. 57 (1) (1997) 41-48.

[37] Z. Zhao, J. Li, A. Kazakov, F. L. Dryer, Temperature-dependent feature sensitivity analysis for combustion modeling, Int. J. Chem. Kinet. 37 (5) (2005) 282-295. 
[38] D. J. Diamantis, E. Mastorakos, D. A. Goussis, $\mathrm{H}_{2}$ /air autoignition: The nature and interaction of the developing explosive modes, Combust. Theor. Model. 19 (2015) 382433.

[39] E.-A. Tingas, D. C. Kyritsis, D. A. Goussis, Comparative investigation of homogeneous autoignition of DME/air and $\mathrm{EtOH} /$ air mixtures at low initial temperatures, Combust. Theor. Model. 21 (1) (2017) 93-119.

[40] D. Goussis, U. Maas, Model reduction for combustion chemistry, in: T. Echekki, N. Mastorakos (Eds.), Turbulent Combustion Modeling, Fluid Mechanics and its Applications, Springer London, 2011, pp. 193-220.

[41] U. Maas, A. S. Tomlin, Time scale splitting-based mechanism reduction, in: F. BattinLeclerc, J. M. Simmie, E. Blurock (Eds.), Cleaner Combustion, Green Energy and Technology, Springer London, 2013, pp. 467-484.

[42] S. H. Lam, D. A. Goussis, Understanding complex chemical kinetics with Computational Singular Perturbation, Proc. Combust. Inst. 22 (1989) 931-941.

[43] S. H. Lam, D. A. Goussis, CSP method for simplifying kinetics, Int. J. Chem. Kinet. 26 (4) (1994) 461-486.

[44] M. Hadjinicolaou, D. A. Goussis, Asymptotic solution of stiff PDEs with the CSP method: the reaction diffusion equation, SIAM J. SCI. COMPUT. 20 (1998) 781-810.

[45] D. A. Goussis, G. Skevis, Nitrogen chemistry controlling steps in methane-air premixed flames, in: K. J. Bathe (Ed.), Computational Fluid and Solid Mechanics, Elsevier, Amsterdam, 2005, pp. 650-653.

[46] D. A. Goussis, H. N. Najm, Model reduction and physical understanding of slowly oscillating processes: the circadian cycle, Multiscale Model. Simul. 5 (4) (2006) 12971332.

[47] T. Lu, C. S. Yoo, J. H. Chen, C. K. Law, Analysis of a turbulent lifted hydrogen/air jet flame from direct numerical simulation with computational singular perturbation, in: 46th AIAA Aerospace Sciences Meeting and Exhibit, Paper AIAA-2008-1013, 2008.

[48] S. H. Lam, D. A. Goussis, Conventional asymptotics and Computational Singular Perturbation for simplified kinetics modelling, in: M. O. Smooke (Ed.), Reduced kinetic mechanisms and asymptotic approximations for methane-air flames, no. 384 in Springer Lecture Notes, Springer-Verlag, Berlin, 1991, pp. 227-242.

[49] F. A. Williams, Lectures on applied mathematics in combustion: Past contributions and future problems in laminar and turbulent combustion, Physica D 20 (1) (1986) 21-34.

[50] J. Buckmaster, P. Clavin, A. Linan, M. Matalon, N. Peters, G. Sivashinsky, F. A. Williams, Combustion theory and modeling, Proc. Combust. Inst. 30 (2005) 1-19. 
[51] T. Lu, C. S. Yoo, J. H. Chen, C. K. Law, Three-dimensional direct numerical simulation of a turbulent lifted hydrogen jet flame in heated coflow: a chemical explosive mode analysis, J. Fluid Mech. 652 (2010) 45-64.

[52] D. J. Diamantis, D. C. Kyritsis, D. A. Goussis, The reactions favoring or opposing the development of explosive modes: auto-ignition of a homogeneous methane/air mixture, Proc. Combust. Inst. 35 (2015) 267-274.

[53] M. Kooshkbaghi, C. E. Frouzakis, K. Boulouchos, I. V. Karlin, n-heptane/air combustion in perfectly stirred reactors: Dynamics, bifurcations and dominant reactions at critical conditions, Combust. Flame 162 (9) (2015) 3166-3179.

[54] M. Valorani, S. Paolucci, E. Martelli, T. Grenga, P. P. Ciottoli, Dynamical system analysis of ignition phenomena using the tangential stretching rate concept, Combust. Flame 162 (8) (2015) 2963-2990.

[55] E. A. Tingas, D. C. Kyritsis, D. A. Goussis, Ignition delay control of DME/air and $\mathrm{EtOH} /$ air homogeneous autoignition with the use of various additives, Fuel 169 (2016) $15-24$.

[56] E. A. Tingas, D. C. Kyritsis, D. A. Goussis, Algorithmic determination of the mechanism through which $\mathrm{H}_{2} \mathrm{O}$-dilution affects autoignition dynamics and $\mathrm{NO}$ formation in $\mathrm{CH}_{4} /$ air mixtures, Fuel 183 (2016) 90-98.

[57] W. Liu, D. Zhu, N. Wu, C. K. Law, Ignition of n-heptane pool by heated stagnating oxidizing flow, Combust. Flame 157 (2) (2010) $259-266$.

[58] H. N. Najm, M. Valorani, D. A. Goussis, J. Prager, Analysis of methane-air edge flame structure, Combust. Theor. Model. 14 (2) (2010) 257-294.

[59] J. Prager, H. N. Najm, M. Valorani, D. A. Goussis, Structure of n-heptane/air triple flames in partially-premixed mixing layers, Combust. Flame 158 (2011) 2128-2144.

[60] Z. Luo, C. S. Yoo, E. S. Richardson, J. H. Chen, C. K. Law, T. Lu, Chemical explosive mode analysis for a turbulent lifted ethylene jet flame in highly-heated coflow, Combust. Flame 159 (1) (2012) $265-274$.

[61] E. A. Tingas, D. C. Kyritsis, D. A. Goussis, Autoignition dynamics of DME/air and EtOH/air homogeneous mixtures, Combust. Flame 162 (9) (2015) 3263-3276.

[62] Z. Wang, B. Chen, K. Moshammer, D. M. Popolan-Vaida, S. Sioud, V. S. B. Shankar, D. Vuilleumier, T. Tao, L. Ruwe, E. Brauer, N. Hansen, P. Dagaut, K. KohseHöinghaus, A. R. Misjudeen, S. M. Sarathy, n-Heptane cool flame chemistry: unraveling intermediate species, Combust. Flame (2017) Under review.

[63] D. A. Goussis, The role of slow system dynamics in predicting the degeneracy of slow invariant manifolds: the case of vdP relaxation-oscillations, Physica D 248 (2013) 16 32 . 
[64] M. Valorani, H. N. Najm, D. A. Goussis, CSP analysis of a transient flame-vortex interaction: Time scales and manifolds, Combust. Flame 134 (1-2) (2003) 35-53.

[65] H. N. Najm, D. Ponganis, J. Prager, Analysis of NO structure in a methane-air edge flame, Proc. Combust. Inst. 32 (1) (2009) 1117-1124.

[66] D. A. Goussis, M. Valorani, F. Creta, H. N. Najm, Reactive and reactive-diffusive time scales in stiff reaction-diffusion systems, Prog. Comput. Fluid Dy. 5 (6) (2005) 316-326.

[67] R. Shan, C. S. Yoo, J. H. Chen, T. Lu, Computational diagnostics for n-heptane flames with chemical explosive mode analysis, Combust. Flame 159 (10) (2012) 3119 - 3127.

[68] R. Shan, T. Lu, A bifurcation analysis for limit flame phenomena of DME/air in perfectly stirred reactors, Combust. Flame 161 (2014) 1716-1723.

[69] D. A. Goussis, H. N. Najm, Model reduction and physical understanding of slowly oscillating processes: The circadian cycle, Multiscale Model. Simul. 5 (2006) 1297-1332.

[70] D. Diamantis, D. Kyritsis, D. A. Goussis, Two stage ignition of n-heptane: Identifying the chemistry setting the explosive time scales, in: 2nd Intl. Conference in Model Reduction in Reacting Flows, 2009.

[71] P. D. Kourdis, A. G. Palasantza, D. A. Goussis, Algorithmic asymptotic analysis of the NF-kB signaling system, Comput. Math. Appl. 65 (2013) 1516-1534.

[72] D. J. Diamantis, D. C. Kyritsis, D. A. Goussis, The reactions supporting or opposing the development of explosive modes: Auto-ignition of a homogeneous methane/air mixture, Proc. Combust. Inst. 35 (1) (2015) 267-274.

[73] D. M. Manias, E. A. Tingas, C. E. Frouzakis, K. Boulouchos, D. A. Goussis, The mechanism by which $\mathrm{CH}_{2} \mathrm{O}$ and $\mathrm{H}_{2} \mathrm{O}_{2}$ additives affect the autoignition of $\mathrm{CH}_{4}$ /air mixtures, Combust. Flame 164 (2016) 111-125.

[74] R. CHEMKIN-PRO, 15112, Reaction Design, Inc., San Diego, CA.

[75] S. M. Sarathy, G. Kukkadapu, M. Mehl, T. Javed, A. Ahmed, N. Naser, A. Tekawade, G. Kosiba, M. AlAbbad, E. Singh, S. Park, M. Al Rashidi, S. H. Chung, W. L. Roberts, M. A. Oehlschlaeger, C.-J. Sung, A. Farooq, Compositional effects on the ignition of FACE gasolines, Combust. Flame 169 (2016) 171-193.

[76] S. S. Merchant, C. F. Goldsmith, A. G. Vandeputte, M. P. Burke, S. J. Klippenstein, W. H. Green, Understanding low-temperature first-stage ignition delay: Propane, Combust. Flame 162 (10) (2015) 3658-3673.

[77] J. Zádor, C. A. Taatjes, R. X. Fernandes, Kinetics of elementary reactions in lowtemperature autoignition chemistry, Prog. Energ. Combust. 37 (4) (2011) 371-421. 
[78] D. Vuilleumier, D. Kozarac, M. Mehl, S. Saxena, W. J. Pitz, R. W. Dibble, J.-Y. Chen, S. M. Sarathy, Intermediate temperature heat release in an HCCI engine fueled by ethanol/n-heptane mixtures: An experimental and modeling study, Combust. Flame 161 (3) (2014) 680-695.

[79] C. K. Westbrook, F. L. Dryer, K. P. Schug, Numerical modeling of ethylene oxidation in laminar flames, Combust. Flame 52 (1983) 299-313.

[80] R. Yetter, I. Glassman, Combustion, Elsevier Science \& Technology, 2008. 